\title{
The Ero Vili and the Atlantic Wall
}

\author{
G. Tomezzoli, Y. Marzin \\ European Patent Office, Munich, Germany \\ Email: gtomezzoli@epo.org, yvan.marzin@gmail.com
}

Received 17 August 2015; accepted 12 October 2015; published 15 October 2015

Copyright $@ 2015$ by authors and Scientific Research Publishing Inc.

This work is licensed under the Creative Commons Attribution International License (CC BY).

http://creativecommons.org/licenses/by/4.0/

(c) (i) Open Access

\begin{abstract}
In this article the events concerning the south portion of the Audierne Bay in the department of Finistère (France) during the $2^{\text {nd }}$ World War are analyzed. The role of the Ero Vili and the Camp Todt in the construction of the Atlantic Wall fortification and the state of preservation of the military and logistic constructions of this portion of the Audierne Bay are presented in order to stimulate further studies by experts and amateurs.
\end{abstract}

\section{Keywords}

$2^{\text {nd }}$ World War, Atlantic Wall, Fortification, Bunkers, Audierne, France, Ero Vili

\section{Introduction}

Located in the department of Finistère (France), at the west of Quimper, the Audierne Bay $\left(47^{\circ} 55^{\prime} 46^{\prime \prime} \mathrm{N}\right.$, $\left.4^{\circ} 23 ' 24^{\prime \prime} \mathrm{W}\right)$ extends itself between the Point of Raz and the Point of Penmarch. Its south portion, low and sandy, between the Point of Penhors and the Point de la Torche, named beach of Tronoën, played, during the $2^{\text {nd }}$ World War, a role of primary importance in the construction of the Atlantic Wall (Dupont \& Peyle, 1994; Chazette, Destouches, \& Paich, 1995; Duquesne, 1976; Lippmann, 1995; Rolf, 1988; Doaré \& Le Berre, 2006). Its important role is witnessed by the impressive remaining of the Acquedut, the yard and the system of fortified sites Wiederstandnesten (Wn) and Stützpunkte (Stp.) controlled by the Kommando Verteidigungsgruppe KVGr. Quimper $(\mathrm{Qu})$.

\section{The Formation of the Ero Vili}

Without going too far back through the geological ages, it is possible to say that the south portion of the Audierne Bay is occupied by an "inferior" dune or "ancient" dune the formation of which, through infiltration of sand, began about 4000 years BC. This dune penetrated until at least 2 to $2.5 \mathrm{~km}$ inland with respect to the current coast line. In the interior the dune has often been leveled and valorized by the agricultural works of proto-historical and Gallo-Roman cultures. The "ancient" dune in some places is about one meter thick. Recent 
dating permitted to conclude that from the Middle Neolithic there have been several important dunes that formed near the Audierne Bay. The "recent" or "living" dune at the current seaside appears already in the old maps of Cassini of 1746-1747, of the Engineers-Geographers of 1780, of Beautemps-Beaupré of 1814-1838 and of the État-Major of 1825-1866. It is almost everywhere superimposed on the "ancient" dune and it buried urns cemeteries and megalithic monuments that existed there. In some places it was used as a quarry, or it was leveled by modern times cultures. Its thrust seems to have begun in the Carolingian period, perhaps around the year $900 \mathrm{AD}$, by small successive increments of 10 to $15 \mathrm{~cm}$ thick, then by larger outbreaks in the course of the successive years and an important step forward a little after the year $1220 \mathrm{AD}$ which determined the formation of a coastal cord of pebbles called in Breton language Ero Vili (Giot, 1998; Boderé, 1973) (cf. Figure 1).

\section{The Aqueduct of Tréguennec}

The Ero Vili protected the land behind the Audierne Bay, but barred a multitude of small streams, preventing them from spilling into the Ocean.

For this reason swamps and ponds were formed along the coast to Trunvel, Kergalan, Nérizellec. Throughout the year, the Ero Vili slowly filtered their water flowing to the Ocean. But in winter, because of heavy rain falls, the water accumulated and regularly invaded lands and houses. Thus, over 500 hectares of land and pastures over six kilometers from the coastline, without counting the edges of streams of the hinterland, turned into swamps. Eager to recover their fields and meadows, the farmers practiced deep grooves in the Ero Vili for water drainage. Before the $2^{\text {nd }}$ World War, every four or five years, the farmers had to tear the Ero Vili, sometimes wide from 30 to 100 meters and several meters high, by means of harrows or planks pulled by horses. The water pressure helped to enlarge the grooves and the water spread on the foreshore. Discharging the water, the grooves closed naturally by the action of storms and waves.

In 1926, under pressure from owners and farmers, the village of Tréogat decided to proceed to a permanent drying out of the marshes and swamps. No less than 123 owners were concerned and a prefectural decree of 1930 united them into an Authorized Trade Union Association. The works were declared of public utility and involved about 300 hectares of farmland. The final project included the digging of a canal network linking the ponds and swamps toward an aqueduct located at a point imposed by the slope (cf. Figure 2 and Figure 3), 150 meters south of the river Trunvel, for spilling into the Ocean all waters of a basin stretched over $62 \mathrm{~km}^{2}$.

The aqueduct had a total length of 120 meters, it was in part protected by the Ero Vili itself and its expected

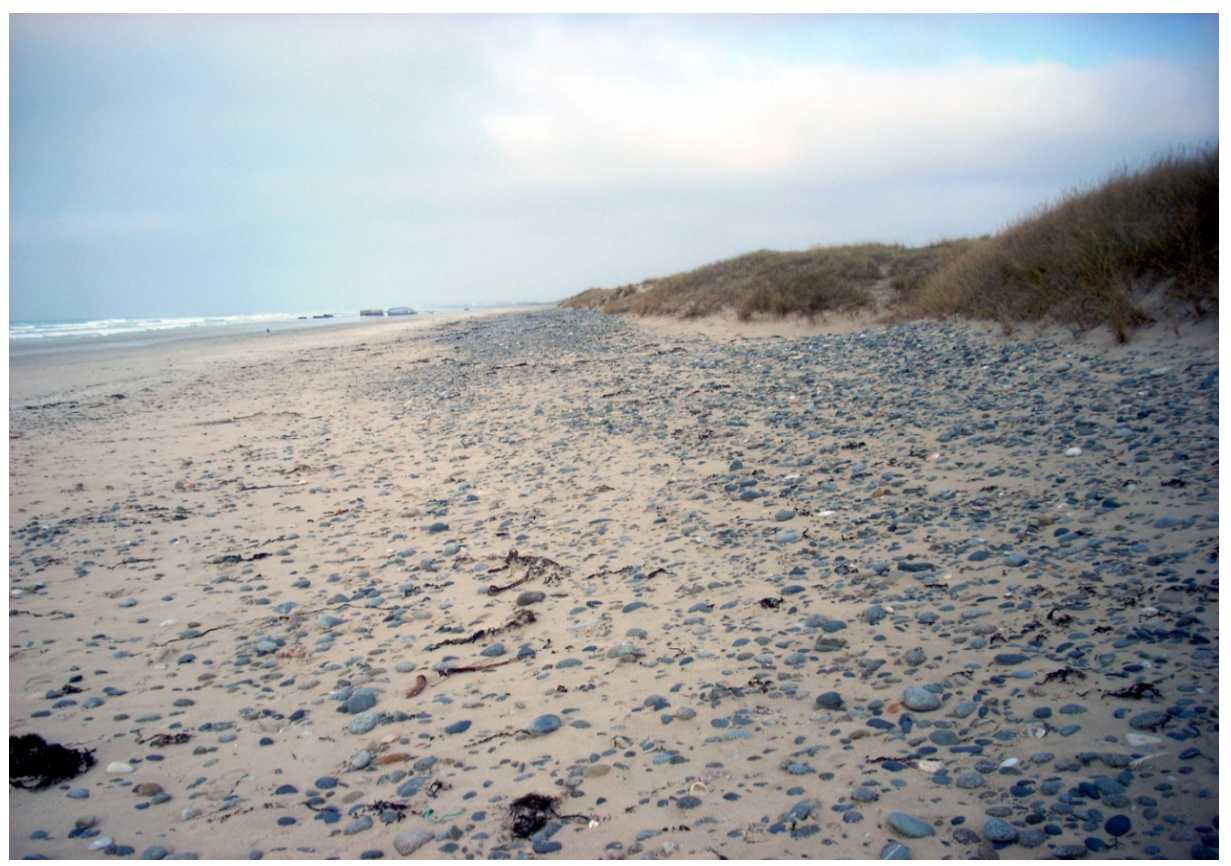

Figure 1. Tronoën beach- "recent" dune and the Ero Vili, the coastal cord of pebbles, on the left, at the horizon the bunkers of the Wn. Qu. 39. 


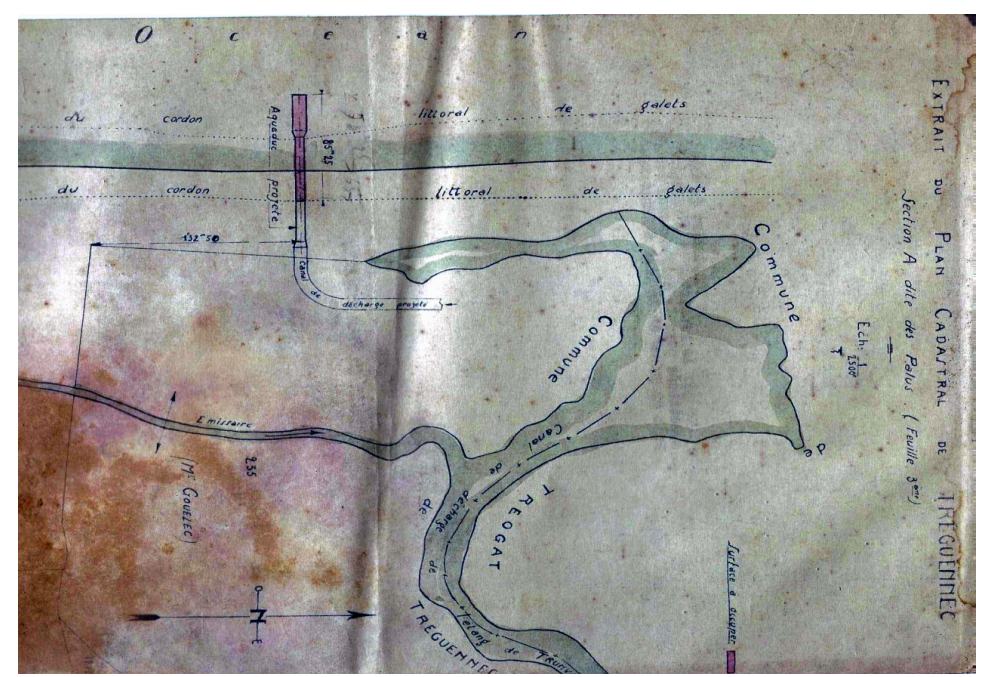

Figure 2. Extract from the Cadastral Map Tréguennec-Section A so-called Swamps (third sheet), on the upper side the aqueduct and the water discharge channel projected.

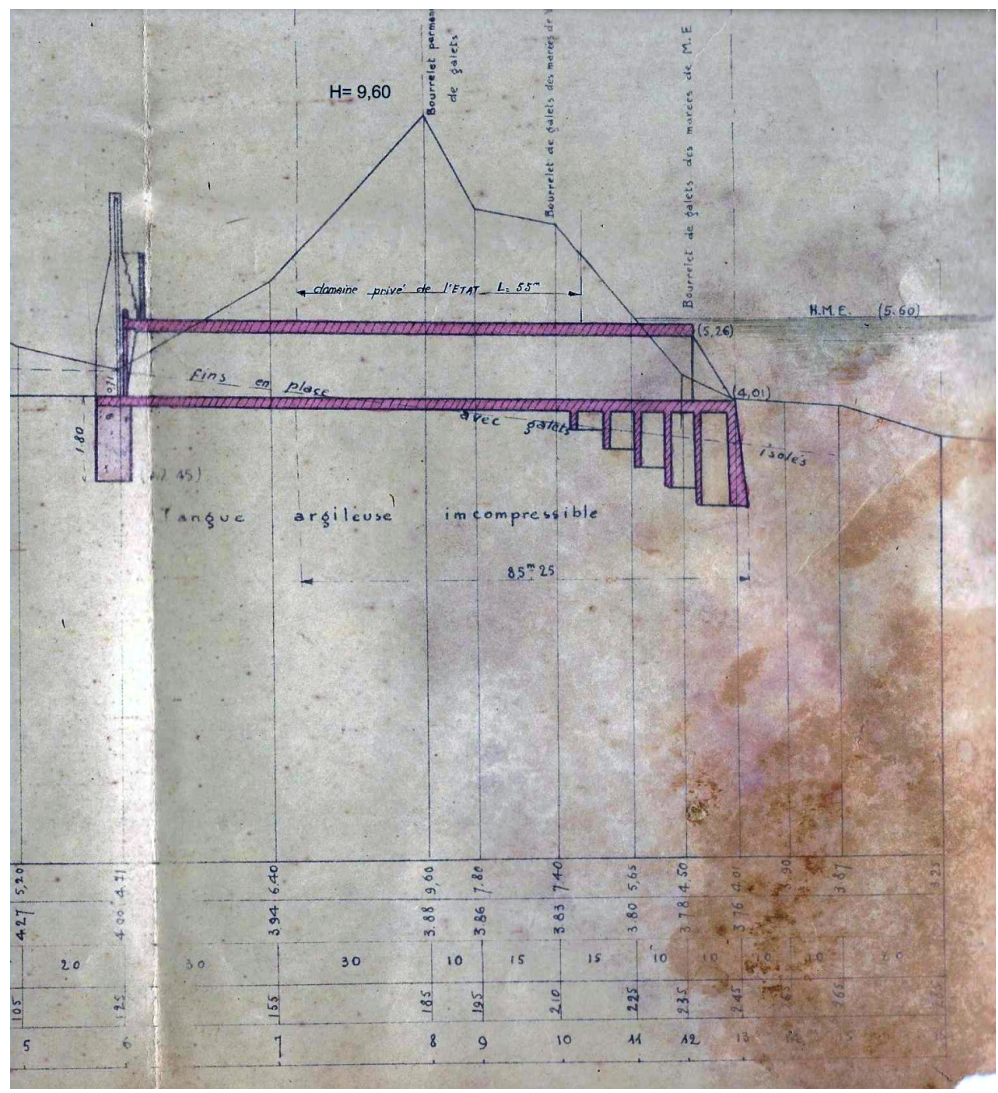

Figure 3. Ero Vili's profile and projected aqueduct — on the left, opening and closing mechanism of the water evacuation doors of the aqueduct.

flow rate was 200 liters/second per $\mathrm{km}^{2}$. Two doors had to regulate the water drainage of the basin.

Noted the erosion of the coast operated by the Ocean, especially during big storms, a prefectural decree of March 1934 banned any exploitation of the Ero Vili, high at that time of about 8 meters and wide from 50 to 100 meters, in all the territory of the Municipality of Plovan, which included much of the Audierne Bay (Vergereau, 
2014).

The work of drying, funded in 1936 by the Agriculture Ministry, debuted in the autumn of 1938. The construction contract was awarded to the entrepreneur Jean-Marie Le Rheun of Tréguennec. At the mobilization, he had to suspend the works.

In 1941, he had built 88 meters of the upstream part of the aqueduct, but the downstream part of it, which had to be a solid maritime work, was entrusted to another entrepreneur.

The arrival of the Organization Todt (O.T.) put a stop to the further prosecution of the drying project. In 1942, surprised by floods which damaged the embankment shaped road connecting the CD156 with the Ero Vili, presumably, the O.T. freed without precaution a huge mass of water retained and the unfinished upstream section of the aqueduct broken.

\section{The Camp Todt}

The construction of Camp Todt on the territory of the Municipality of Tréguennec is related to the Ero Vili and the decision taken by Hitler by the Directive of 14 December 1941 to entrust the O.T. with the construction of the Atlantic Wall.

In February 1942 the Finistère prefect received by the Feldkommandantur Quimper, responsible for the Audierne sector, the order to provide the O.T. with "200 fully skilled workers" for a period of three months involving concreters, carpenters, machinists, crane operators, ..., as well as persons qualified in maneuvering, for the works of construction of a Kieswerk or yard of extraction and crushing of pebbles at a place called Prat ar Hastel (Vergereau, 2014) on the Municipality of Tréguennec, near the Ero Vili (cf. Figure 4). The pebbles and the crushed pebbles entered in the concrete composition for the bunkers of the Atlantic Wall (Chazette et al., 1995; Dupont \& Peyle, 1994; Duquesne, 1976; Lippmann, 1995).

A reduced gauge railway line abandoned since December 31, 1934, was widened to standard gauge and elongated by the National Society of Railways (SNCF) and the O.T. so as to connect the yard to the station of Pen-Enez near Pont l'Abbé (Bohn, 2014) and then to Quimper.

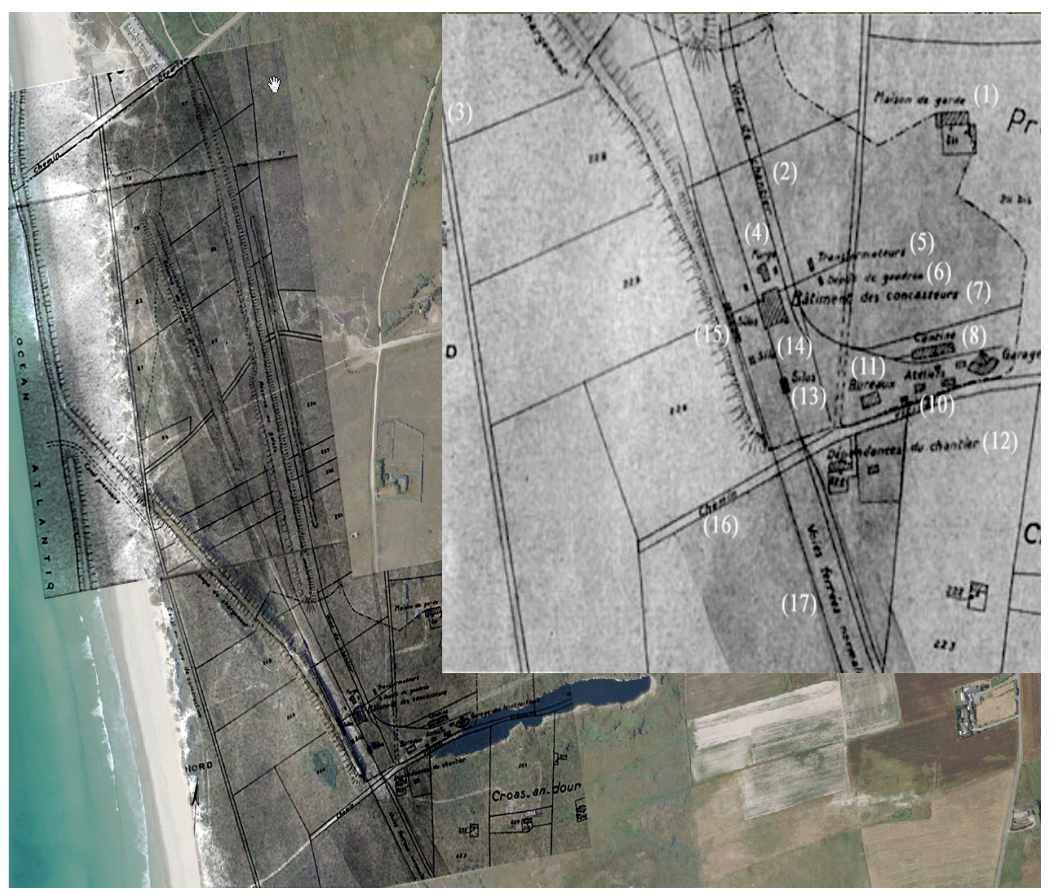

Figure 4. On the left the Ero Vili exploitation and right the Camp Todt: (1) guard house, (2) ways of the yard, (3) channel in construction, (4) forge, (5) electrical transformers, (6) allpurpose depot, (7) crusher building, (8) canteen (9), loco-tractors garage, (10) workshop barracks, (11) office barrack, (12) dependencies of the yard, (13) silo, (14) silo, (15) screening silos, (16) coast path and (17) normal gauge railways. 
In service, 3000 effectives worked night and day in the yard. They were mainly local workers of the Compulsory Work Service (STO), but also Russian and Polish prisoners. A bulldozer Caterpillar pushed the pebbles towards two excavators Weserhutte. The excavators loaded the pebbles on convoys of wagonettes and a locomotive Decauville brought each convoy on the high of a massive, reinforced concrete wall about 150 meters long, about 2 meters wide and about 10 meters high. About 130 wagonettes were in service at the yard. From that height, workers manually toppled each wagonette so as to drop the pebbles into three, later five, screening silos. From the silos, the small pebbles directly usable in construction fell into a convoy of wagons parked at the bottom of the wall. By means of a locomotive, each convoy left the yard for Pen-Henez. The too large pebbles not usable in the state, were collected in convoys of wagonettes driven by loco-tractors and stored outside the crushers building (about $20 \times 13$ meters) of the yard. The building (cf. Figure 5) had two floors and was built of wood, concrete and bricks and included a gantry crane. The yard run for a period of about two years by reason of four to six, sometime eight, trains of 500 tons per day (Vergereau, 2014; Bohn, 2014; Pennmarc'h, 2014; Le Berre, 2008). Conveyor belts brought the pebbles towards three horizontal jaw crushers and to a vertical cylinder crusher entered service in 1944, all located inside the building. The pebbles were sometimes so hard that caused failures of the crushers. The crushed pebbles were stored in a first concrete silo with four compartments inside the building (cf. Figure 6) and in a second silo (about $10 \times 5.40$ meters) of reinforced concrete provided with five hoppers at about 30 meters from the building. A train rail ran under and alongside the silos for loading the crushed pebbles on SNCF dumper wagons. The daily water requirement for the operation of the yard was about $150 \mathrm{~m}^{3}$. The pumping was made from a nearby stream whose flow was $50 \mathrm{~m}^{3} /$ hour (Bohn, 2014). Figure 4 shows the organization of Camp Todt and the exploitation plane of the Ero Vili which extended well beyond the current beach.

Figure 5 couples two shots of Camp Todt of 1946. Visible are: the massive, reinforced concrete wall with metal protective barrier on which the convoys of wagonettes were routed; the crushers building with possible watchtower, which masks the screening silos; the second silo with conveyor belt for crushed pebbles; a convoy of wagonettes next to the crusher building and conveyor belts to move up to the pebbles inside the building. On the upper shot, behind the crusher building are visible the forge barrack and in the foreground are visible the electrified barrier of the Camp, the office barrack and two work shop barracks. Between the two work shop barracks, four workers are constructing a line with reduced gauge for wagonettes; behind them an excavator bucket. On the lower shot, behind the silo is visible an excavator Weserhutte. With the progression of the war and the progress of the construction of the Atlantic Wall, in 1943-44 near the beach of Tronoën were built the fortified points Wn. Qu. 39, Wn. Qu. 40 (cf. Figure 7) adapted for close defence of the Camp Todt, Wn. Qu. 32, Wn. Qu. 41 and Wn. Qu. 42 (cf. Figure 8).

Far from Normandy, the Tronoën beach was never interested by important combats. However, in the night between 11 and 12 August 1944 three German patrol vessels directed to Lorient along the coast of the Audierne Bay were intercepted by five allied destroyers. Two damaged vessels were able to escape, but the third damaged and in fire run aground near the Camp Todt. In the night between 22 and 23 August 1944 seven German patrol vessels in two convoys trying to reach Lorient were blocked in the Bay and put out of combat by the cruiser HMS Mauritius and the destroyers HMS Ursa and HMSC Iroquis of the Kinetic Force 27. Later in the night also a German minesweeper was destroyed. The Allied never bombed the yard; there was only some strafing at the end of the war (Figures 9-11).

The Germans abandoned the Camp Todt in the late July 1944, at the moment of the Liberation. After the Liberation, the French Military Engineer Service and the French Civil Service of Bridges and Roadways used $100,000 \mathrm{~m}^{3}$ of not yet crushed pebbles for the reconstruction of the city and the port of Brest (Bohn, 2014). The exploitation of the Ero Vili stopped in the late 1947. Purchased in October 1949 by a private company to process the minerals extracted from a nearby quarry, the yard was used until the early 70s (Pennmarc'h, 2014).

The exploitation of the Ero Vili has caused the advancement of the erosion of the coast so that the Wns, built once sheltered between the dunes near the coast are now on the Tronoën beach exposed tides and storms.

\section{Survey of the Civilian and Military Facilities of the Tronoën Beach}

We are glad that a tourist excursion on December 30,2010, suggested by a work colleague, and others successive excursions in the following months have transformed into a unique opportunity to study the remains of the aqueduct, the Camp Todt, and the German Wns. on the Tronoën beach (cf. Figure 12). 

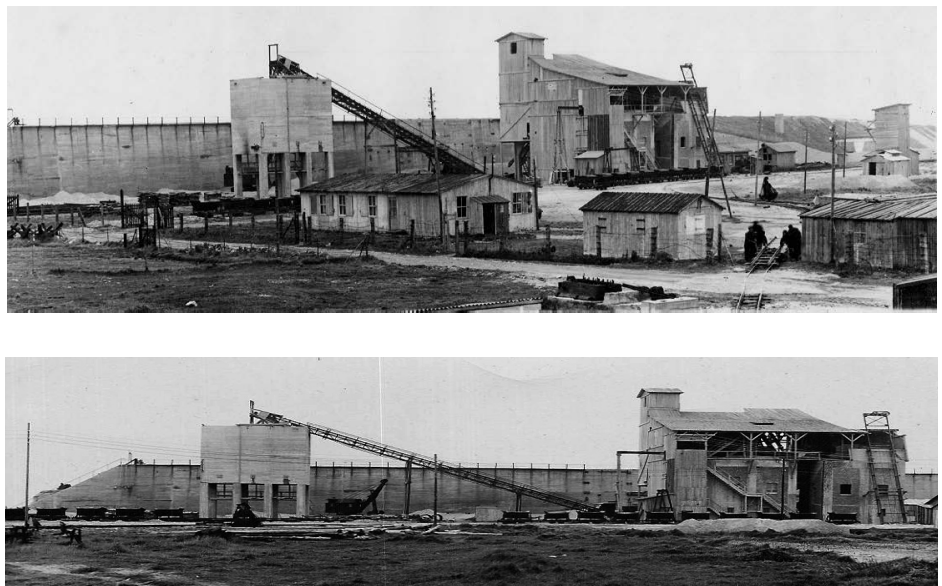

Figure 5. Camp Todt- two shots of 1946.

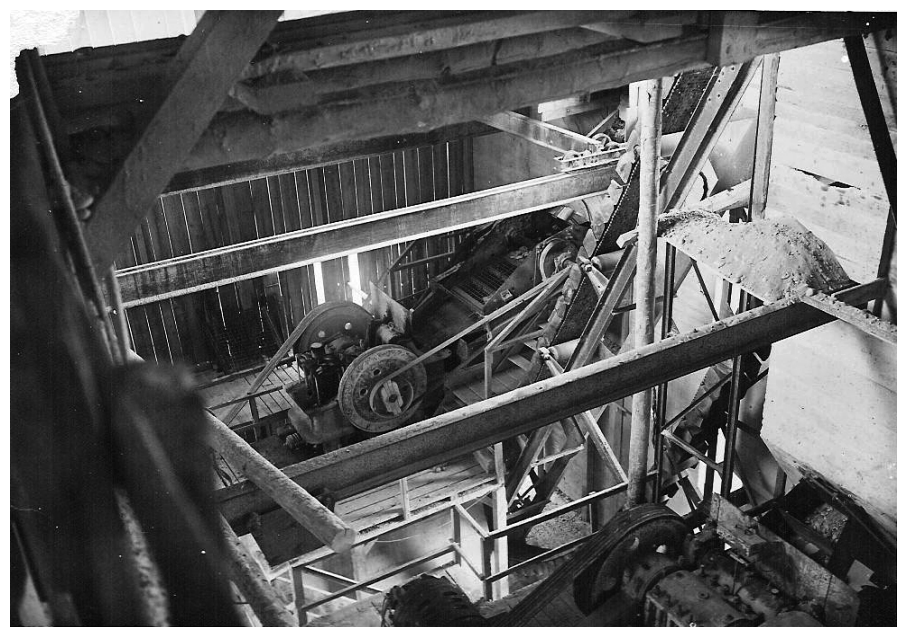

Figure 6. Interior of the crusher building-loading mechanism of crushed pebbles in the first concrete silo.

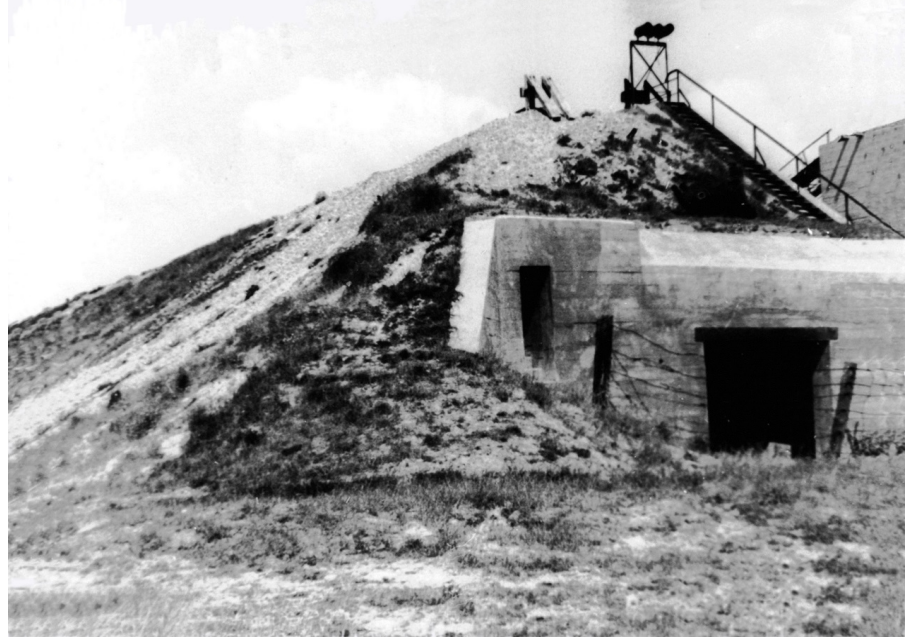

Figure 7. Wn. Qu. 40-bunker H672 of Wn. Qu. 40 at the end of the massive wall, on the left entrance of the tobruck annexed to the bunker, on the right staircase leading straight to the top of the wall and the second silo. 


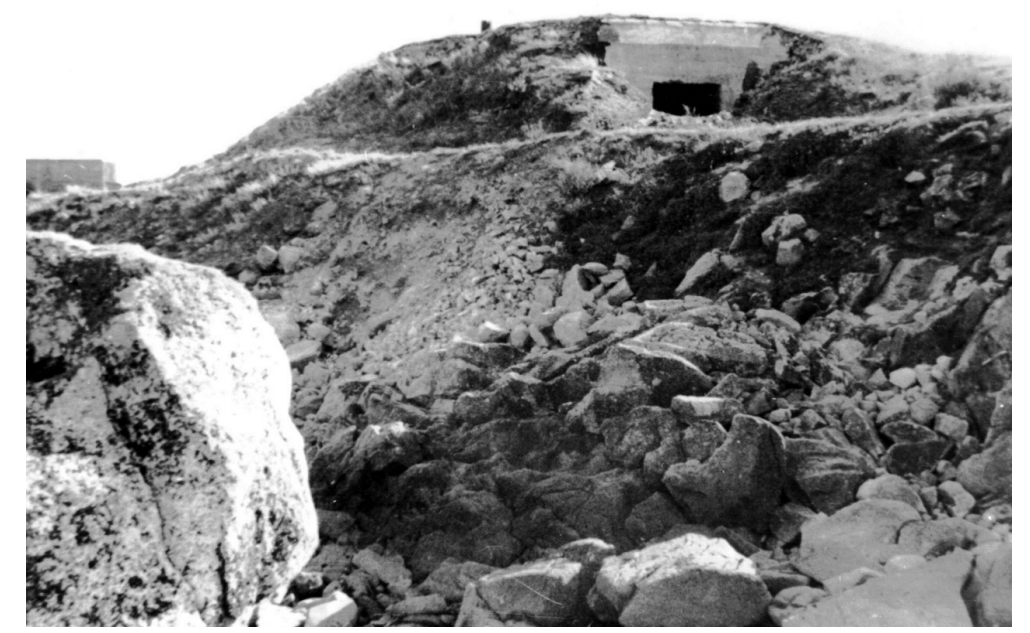

Figure 8. Wn. Qu. 42-Vk bunker of Wn. Qu. 42 camouflaged among the rocks.

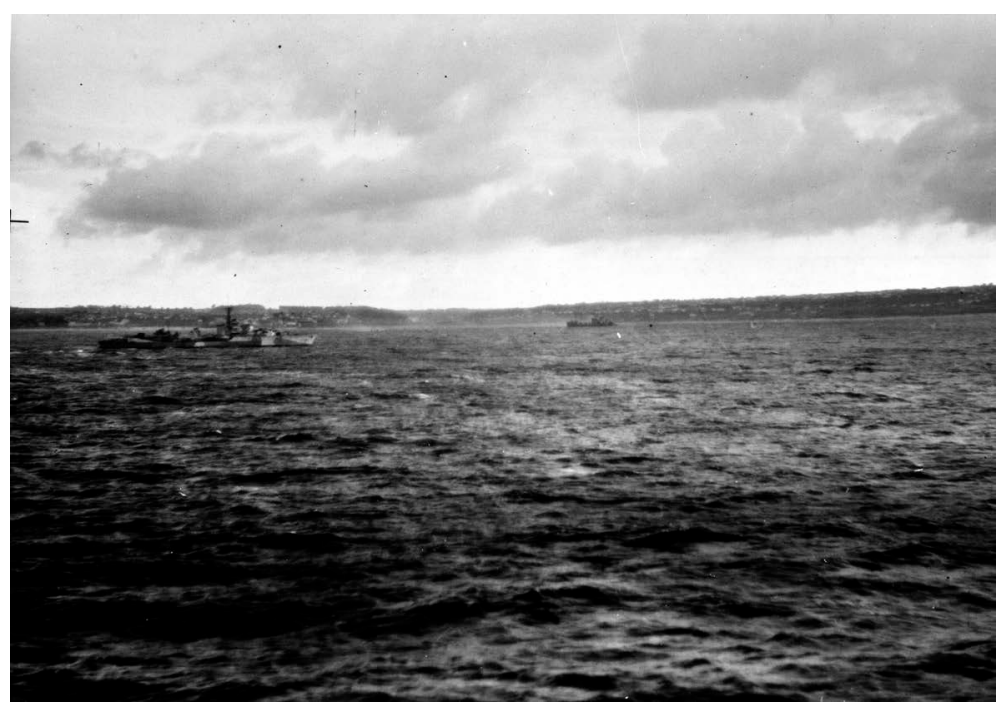

Figure 9. Battles of the Audierne Bay-23/08/1944 on board HMS Mauritius, on the left British destroyer in the middle, at the horizon German patrol vessel-IWM A_025322.
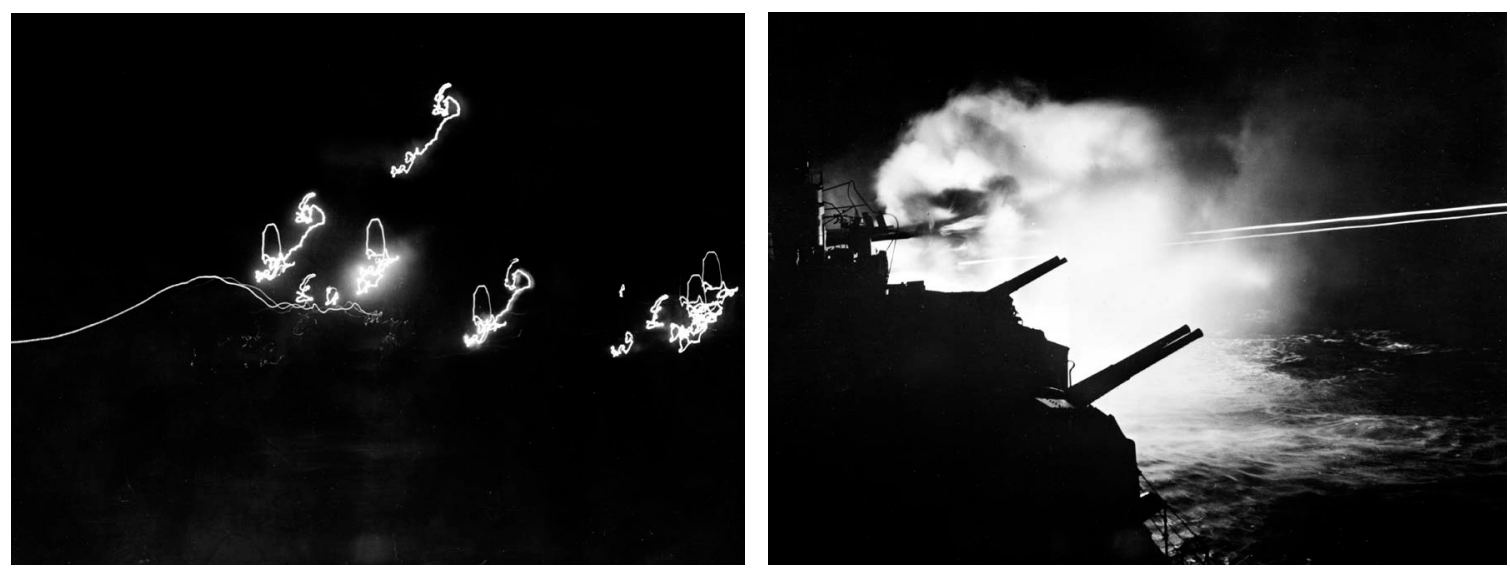

Figure 10. Battles of the Audierne Bay - night combat—star shell illuminating the targets and firing of the 6-inch guns of HMS Mauritius-IWM A_025320, IWM A_025321. 


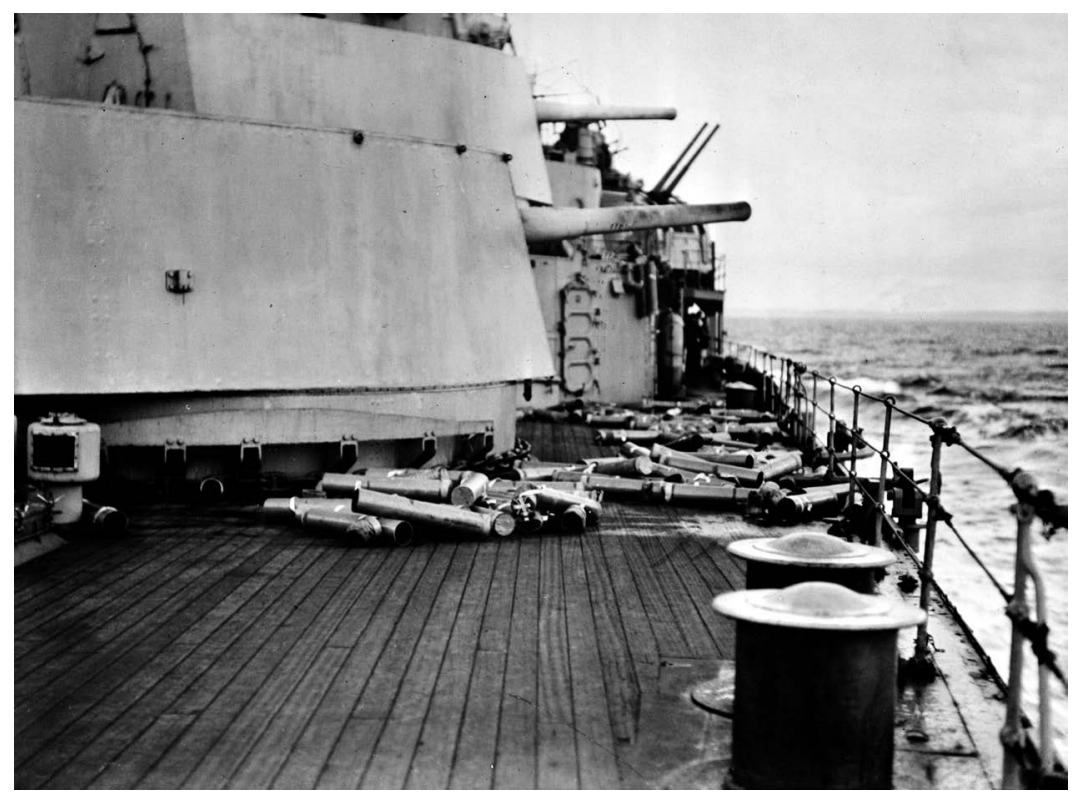

Figure 11. Battles of the Audierne - empty shell cases on the quarterdeck of the HMS Mauritius_IWM A_025323.

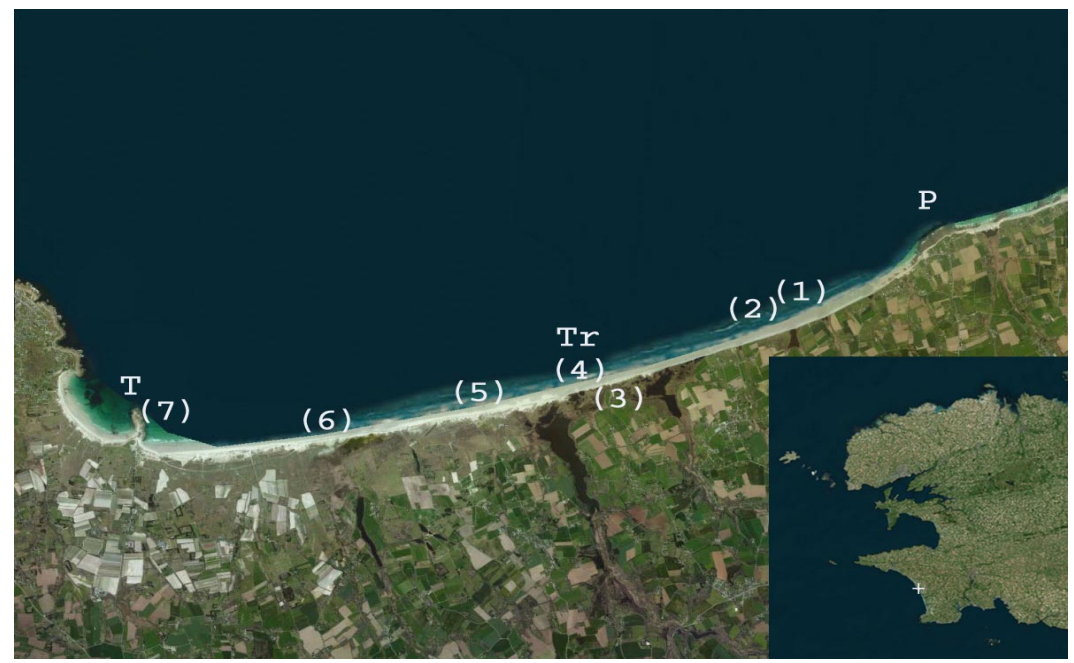

Figure 12. Southern part of the Audierne Bay—P Penhors Point, Tr Tronoën beach, T Point de la Torche, (1) aqueduct, (2) Wn. Qu. 39, (3) CampTodt, (4) Wn. Qu. 40, (5) Wn. Qu. 32, (6) Wn. Qu. 41 and (7) Wn. Qu. 42 (Flash Earth).

Vestiges of the aqueduct $\left(47^{\circ} 53^{\prime} 11.2^{\prime \prime} \mathrm{N}, 4^{\circ} 21^{\prime} 48.7^{\prime \prime} \mathrm{W}\right)$

During the visits, on the aqueduct site we identified the upstream part of it (cf. Figures 13-15) about 50 meters long and about $5 \mathrm{~m}$ wide, formed by three concrete components: the component (1) about $25 \mathrm{~m}$ long, the component (2) about $15 \mathrm{~m}$ long, almost completely covered by sand and probably broken in two places and the component (3) about $4 \mathrm{~m}$ long with the possible location of the opening and closing mechanism of the doors with protective wall. The sand has completely invaded the inner pipe of the aqueduct.

Vestiges of the Wn. Qu. $39\left(47^{\circ} 52^{\prime} 58.0^{\prime \prime} \mathrm{N}, 4^{\circ} 21^{\prime} 42.4^{\prime \prime} \mathrm{W}\right)$

The Wn. Qu. 39 (cf. Figures 16-23) is the best preserved of the Wns. on the Tronoën beach. On the site we identified: a bunker H134 (Munitions unterstand); a H501 (Gruppen unterstand) with protection wing and annexed tobruk; a $\mathrm{H} 667$ for a $5 \mathrm{~cm} \mathrm{KwK}$ gun with protective wall, two tobruk H58c for machine gun $\mathrm{Mg} 42$, a Vf600v for a $5 \mathrm{~cm} \mathrm{KwK} 39$ gun and covered trenches.

The bunkers showed no damage due to fighting and it cannot be said whether they maintained their original, relative positions and whether other bunkers disappeared into the Ocean or remain buried under the sand. 


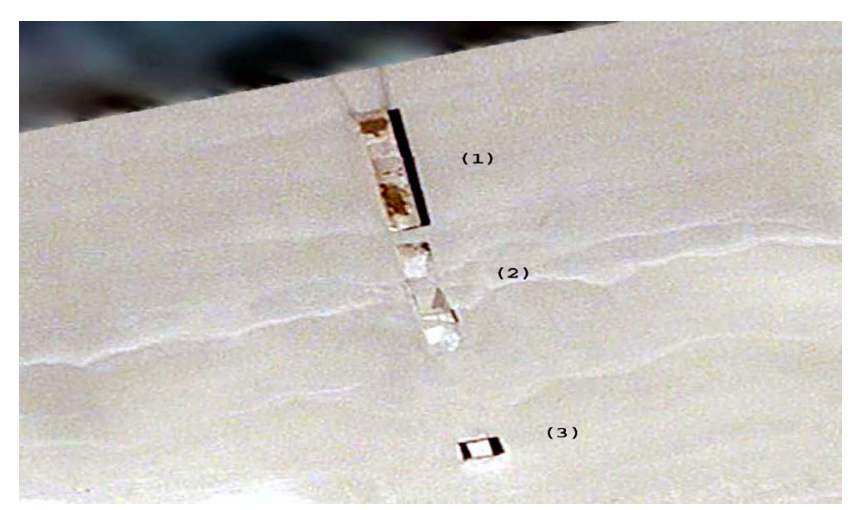

Figure 13. Aqueduct components (1) - (3) (Flash Earth).
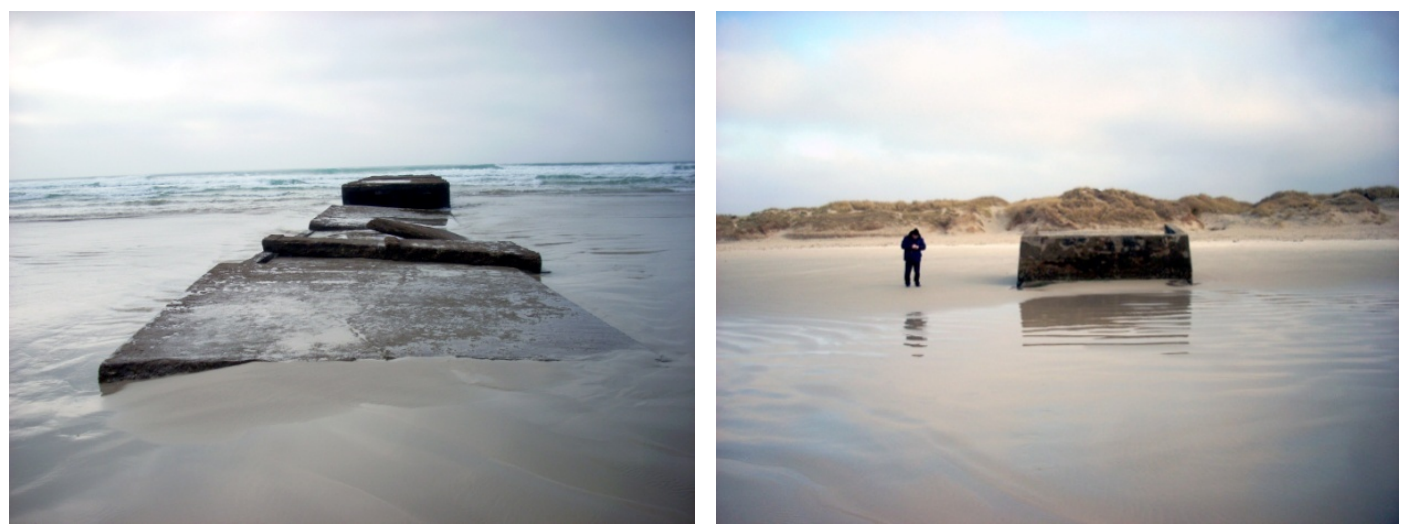

Figure 14. Aqueduct components (1) and (3).

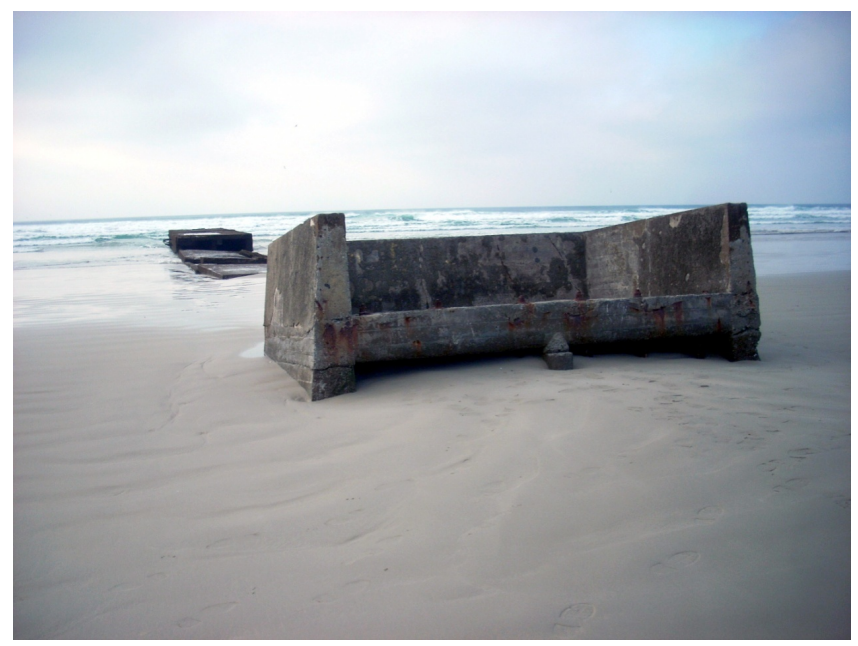

Figure 15. Aqueduct component (3) with the possible location of the opening and closing mechanism of the doors with protective wall, on the left component (1) and between the two, the component (2) covered by sand.

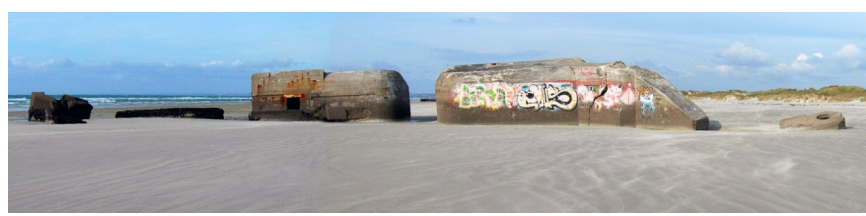

Figure 16. Wn. Qu. 39 - south view, from left to right: Vf600v, covered trench, H134, H501 with graffiti and H58c. 


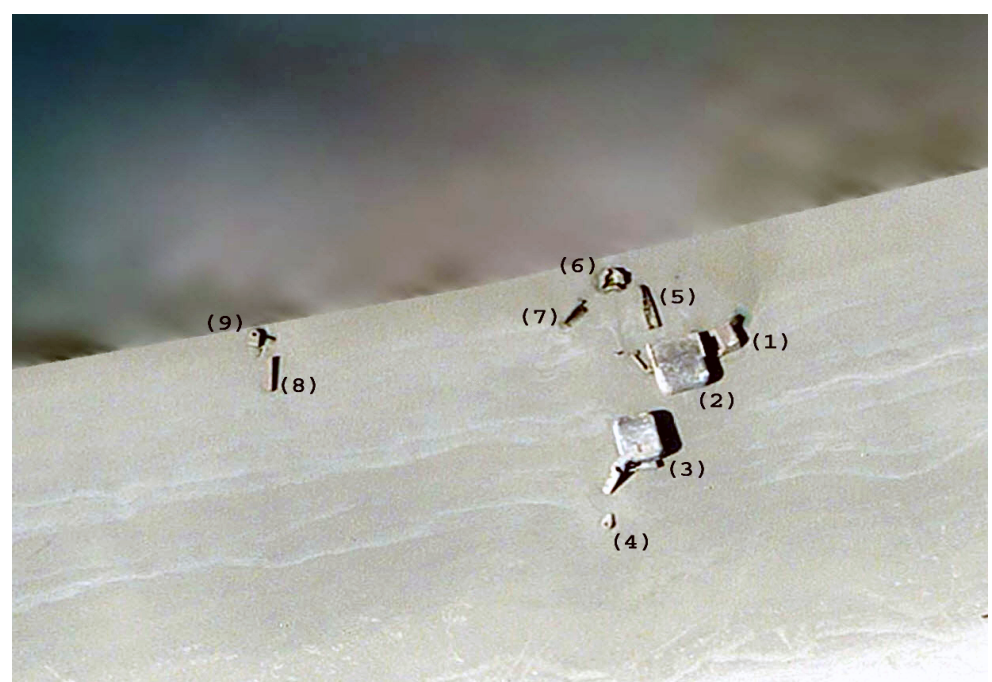

Figure 17. Wn. Qu. 39 - general organization: (1) H667, (2) H134, (3) H501, (4) (9) H58c, (5) (7) (8) covered trenches and (6) Vf600v (Flash Earth).

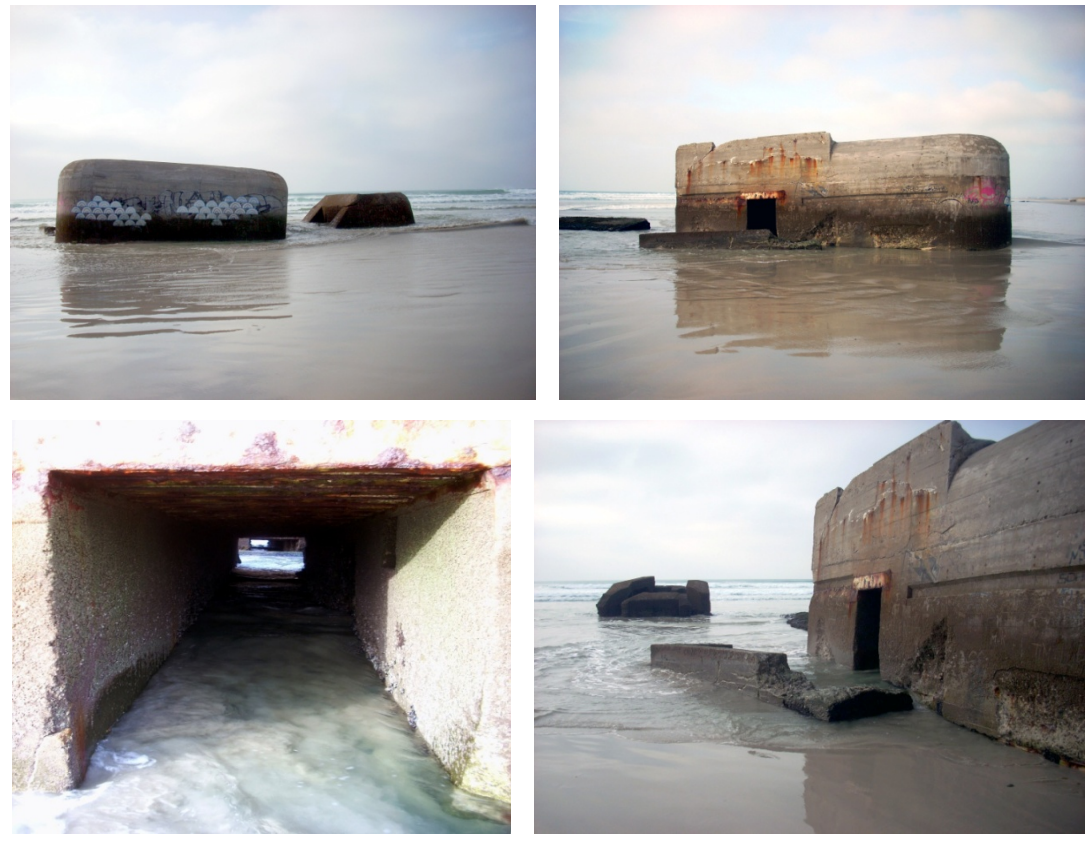

Figure 18. Wn. Qu. 39 - details of the H134-visible are also the H667, a covered trench and the Vf600v.
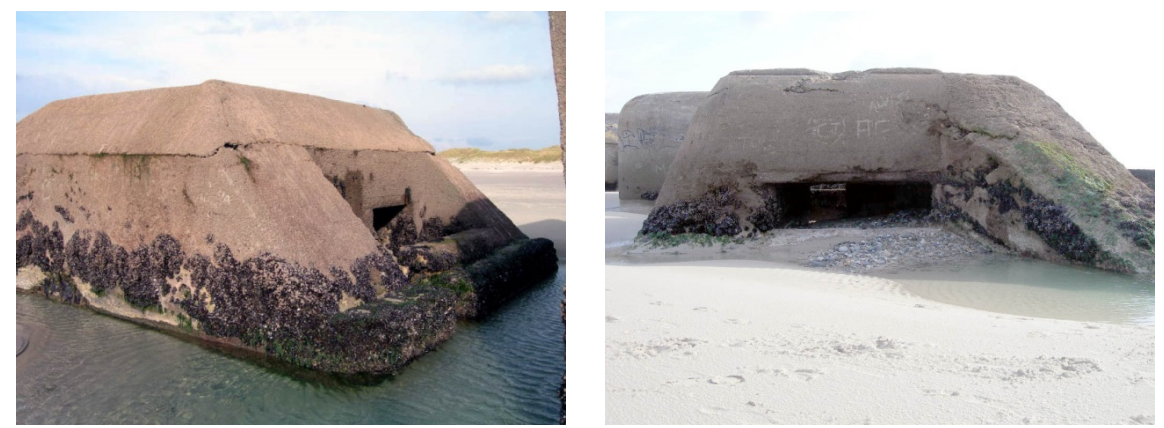

Figure 19. Wn. Qu. 39- details of the H667-entrance and embrasure of the firing chamber with protective wing. 


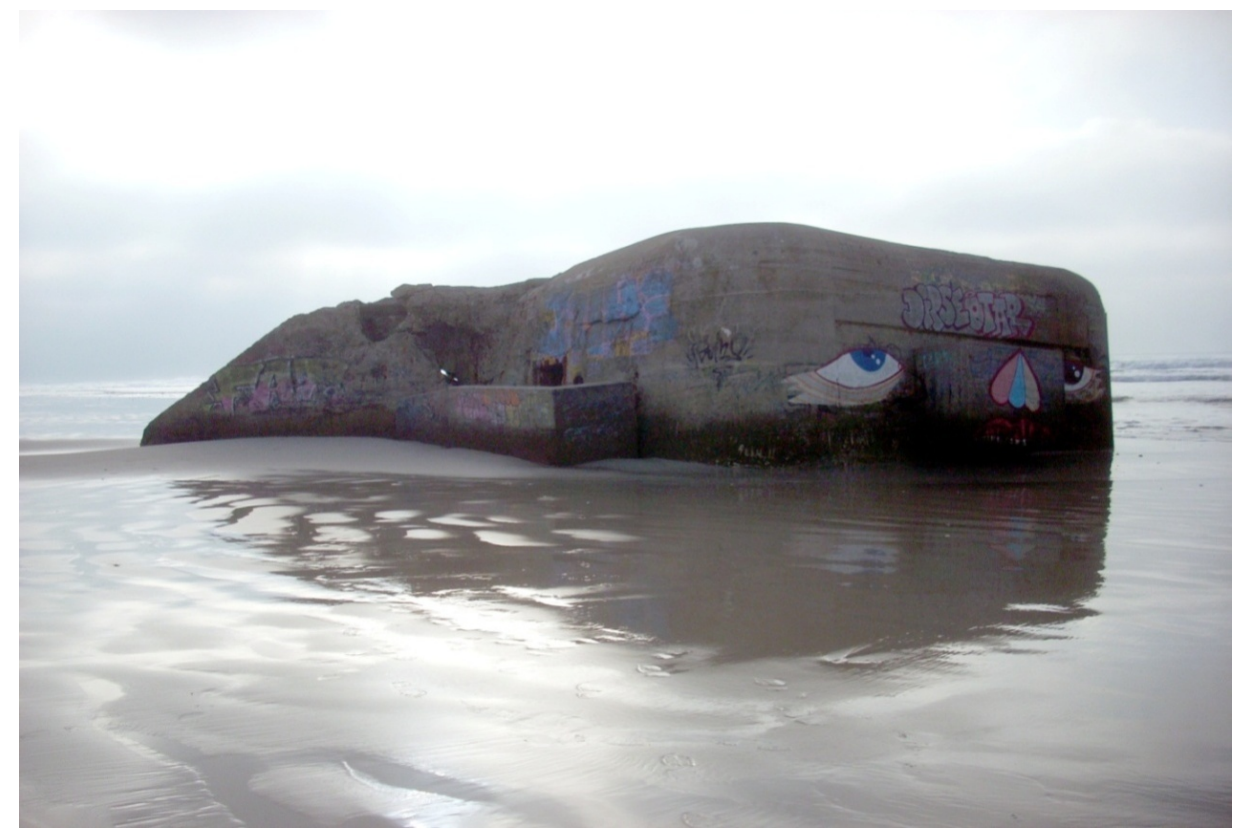

Figure 20. Wn. Qu. 39 - details of the H501: on the left protection wing with opening of the tobruck for machine gun, at the center entrance with protective wall.
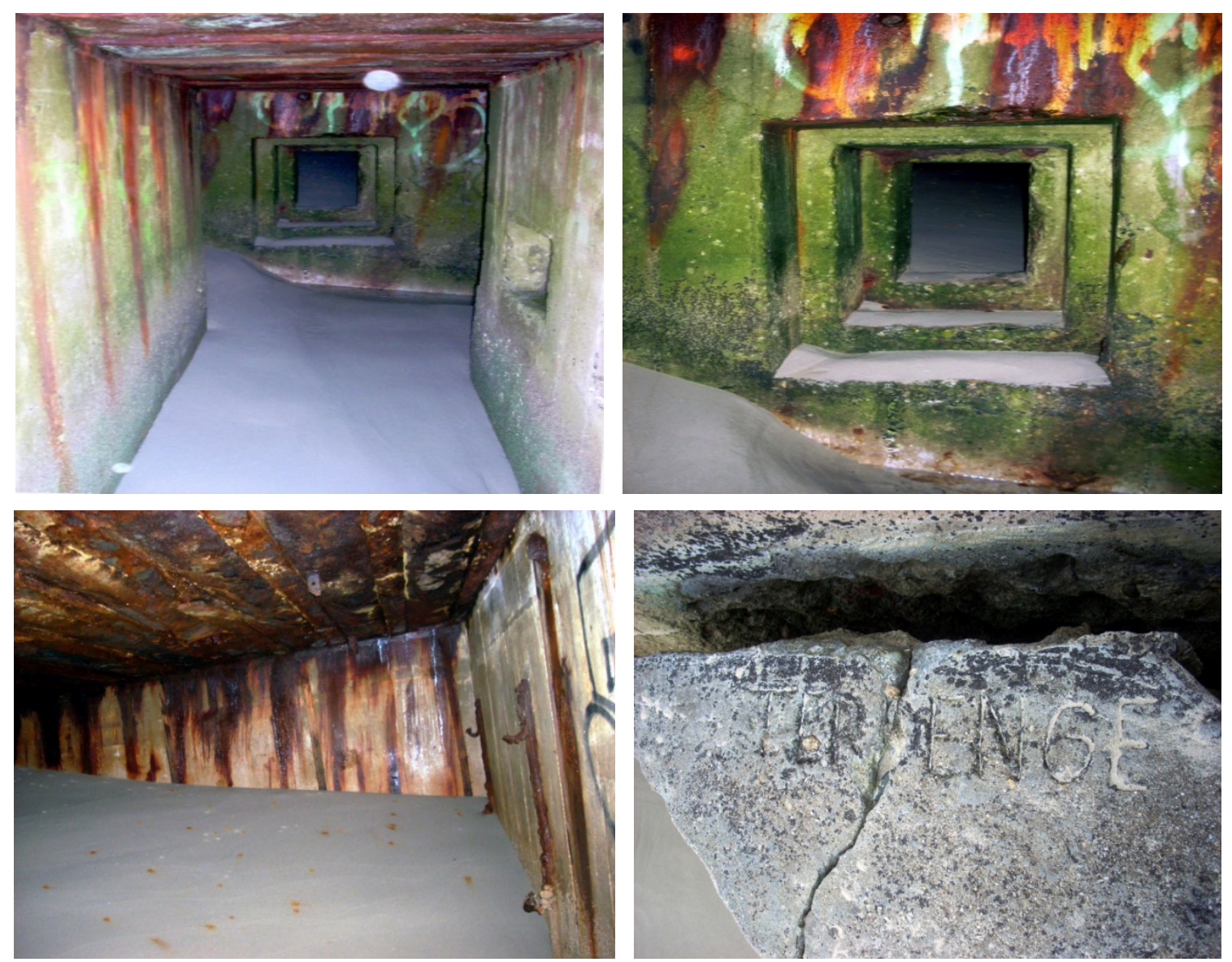

Figure 21. Wn. Qu. 39 - details of the inside of theH501 - access corridor with embrasure, bunk beds supports for the troop, engraved in scription or TER (?) ENGE or TER (?) EN6E. 

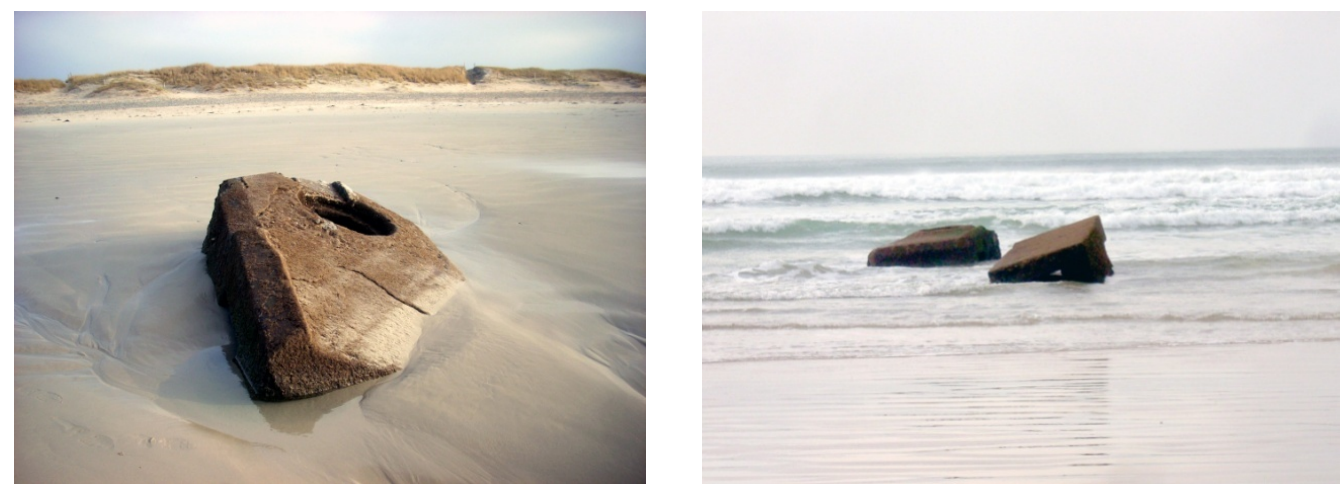

Figure 22. Wn. Qu. 39-H58c (4) and H58c (9) with a covered trench (8).

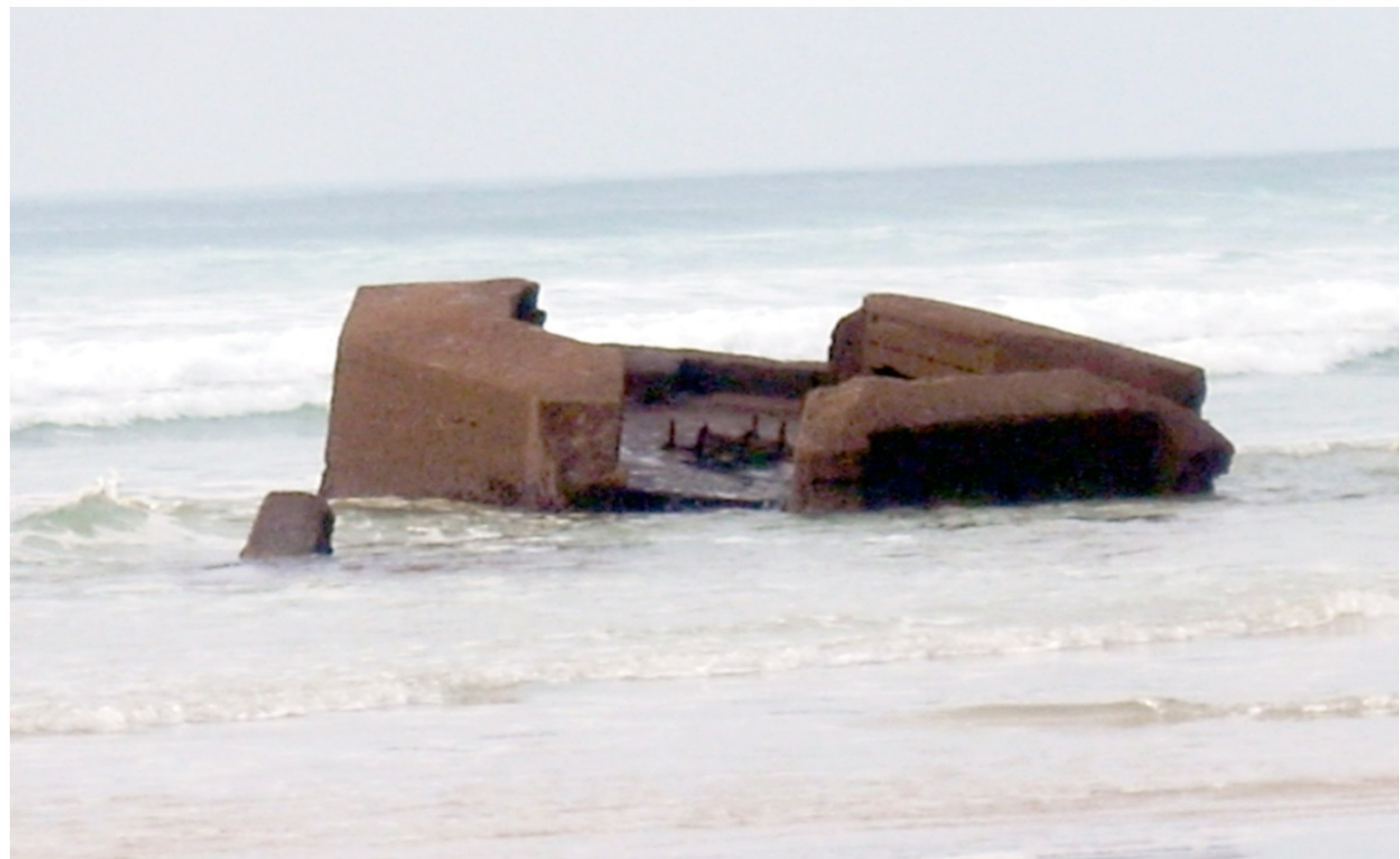

Figure 23. Wn. Qu. 39-Vf600v visible are the mounting studs for the gun $5 \mathrm{~cm} \mathrm{KwK39.}$

\section{Vestiges of the Camp Todt $\left(47^{\circ} 52^{\prime} 29.7^{\prime \prime} \mathrm{N}, 4^{\circ} 21^{\prime} 11.8^{\prime \prime} \mathrm{W}\right)$}

On the Camp Todtsite we identified (cf. Figures 24-32): the massive wall, the remains of the crusher building comprising the electrical distribution cabin devoided of all its devices, the compartments of the crushers, the first silo, the concrete supports for the loading mechanism of the crushed pebbles in the first concrete silo; and the second silo. Crushers, conveyors, railway lines and barracks have disappeared.

Vestiges of the Wn. Qu. $40\left(47^{\circ} 52^{\prime} 29.7^{\prime \prime} \mathrm{N}, 4^{\circ} 21^{\prime} 11.8^{\prime \prime} \mathrm{W}\right)$

The Wn. Qu. 40 (cf. Figures 33-37) extended mainly on the part of the massive wall opposite to the crusher building (cf. Figure 29) and presents a remarkable different organization (cf. Figure 25 and Figure 34) with respect to the other Wns. (cf. Figure 17, Figure 39, Figure 44 and Figure 45). On the site we identified: a H672 gun shelter with annexed tobruch for MG machine gun, three Vf4b for MG machine gun and a Vf61a mortar tobruck. The entries of the H672 and the tobruk annexed (cf. Figure 32) have been curled with sand, leaving impossible the exploration bunker inside. The sand covers also the Vf4bs and the internal connection passage except the surveillance bunker at the end of the massive wall formed by two coupled Vfs (cf. Figure 24 and Figure 25). The H672 seems not connected to said internal passage.

The exploration has revealed that the connection passage and the Vfs maintain a good state of preservation, but that all the original equipment and weapons disappeared. 
Vestiges of the Wn. Qu. $32\left(47^{\circ} 52^{\prime} 06.6^{\prime \prime} \mathrm{N}, 4^{\circ} 21^{\prime} 18.3^{\prime \prime} \mathrm{W}\right)$

The Wn. Qu. 32 (cf. Figures 38-43) appears well preserved and shows the same organization of the Wn. Qu. 39. On the site we identified only: a H134, aH501, a H667 and a H58c. Accordingly, a further H85c, a Vf600v and covered trenches were either never built, or buried in the sand or disappeared in the Ocean. After the war, the use of the $\mathrm{H} 667$ as shelter for the detonation of unexploded mines and bombs stacked inside, and the action of tides and storms explain its poor state of preservation (cf. Figure 38 and Figure 40).

Vestiges of the Wn. Qu. $41\left(47^{\circ} 51^{\prime} 12.9^{\prime \prime} \mathrm{N}, 4^{\circ} 20^{\prime} 59.1^{\prime \prime} \mathrm{W}\right)$

The Wn. Qu. 41 (cf. Figure 44) is the worst preserved of the Wns. on the Tronoën beach and shows the same organization of the Wn. Qu. 39 and the Wn. Qu. 32. On the site we identified only: a H667 and a H134. Accordingly: a H501, two H58c, a Vf600v and covered trenches were either never built, or buried in the sand or disappeared in the Ocean.

Vestiges of the Wn. Qu. $42\left(47^{\circ} 50^{\prime} 14.2^{\prime \prime} \mathrm{N}, 4^{\circ} 21^{\prime} 05.1^{\prime \prime} \mathrm{W}\right)$

The construction on the Pointe de la Torche of the Wn. Qu. 42 (cf. Figures 45-50) involved the destruction of the of prehistoric settlements remains (4). On the site we identified: three H85c, a H611for field-gun, a Vk Pak and a H501.The orientation of Vk Pak and H611 northward allowed their guns to support the shooting of the other Wns. and so to defend almost the entire Tronoën beach.

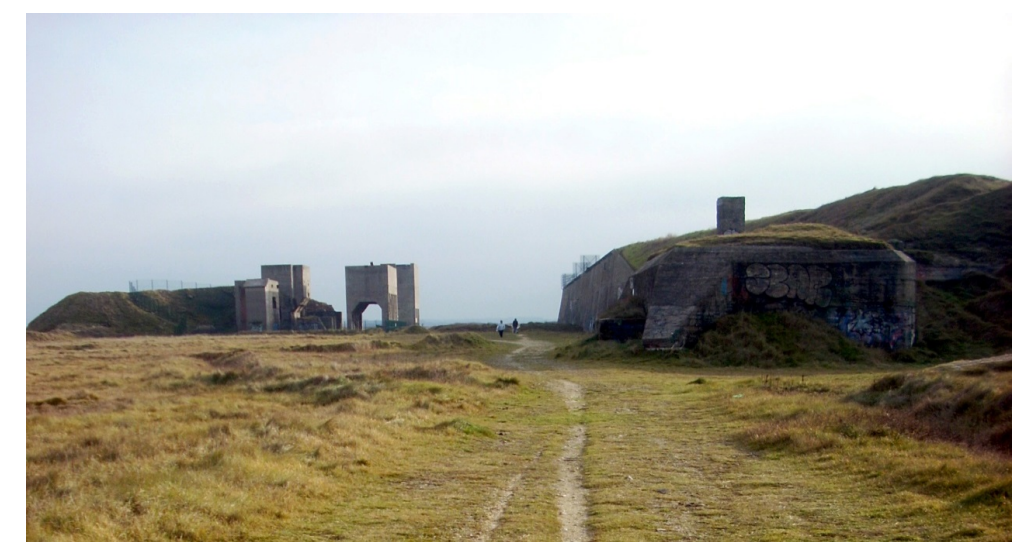

Figure 24. Camp Todt and Wn. Qu. 40 - on the left, remains of the crusher building with first and second silo, in the middle the massive wall of the Camp Todt, on the right surveillance bunker Vf with high air intake/emergency exit of the Wn. Qu. 40 internal passage.

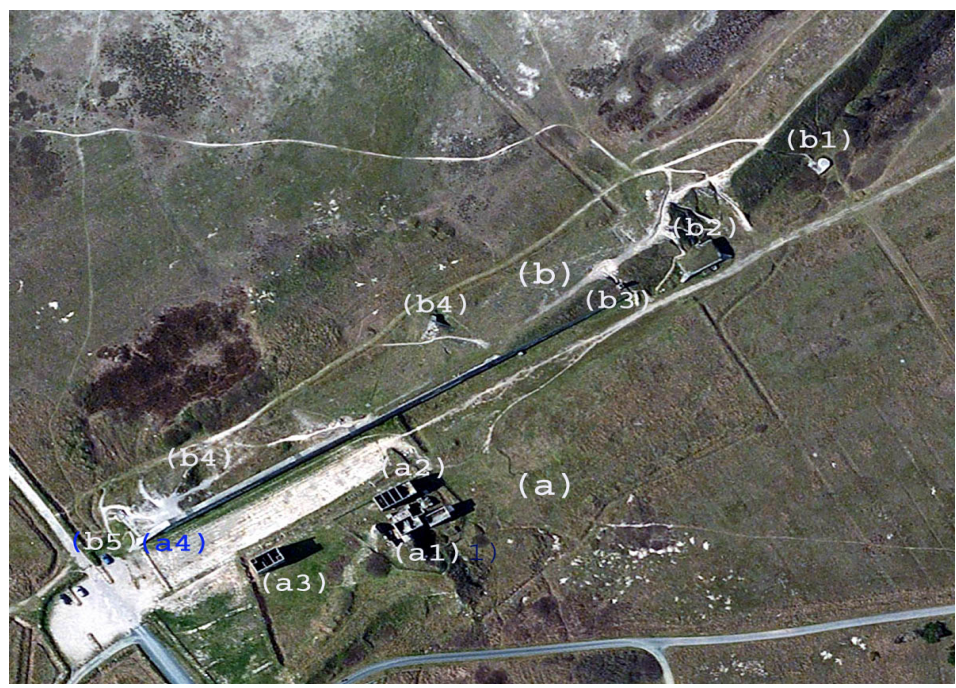

Figure 25. Camp Todt and Wn. Qu. 40 - (a) Camp Todt: (a1) vestiges of the crusher building, (a2) first silo, (a3) second silo, (a4) massive wall; (b) Wn. Qu. 40: (b1) tobruck for mortarVf61a, (b2) surveillance bunkers Vf, (b3) air intake/emergency exit, (b4) Vf bunkers and (b5) bunker H672. 

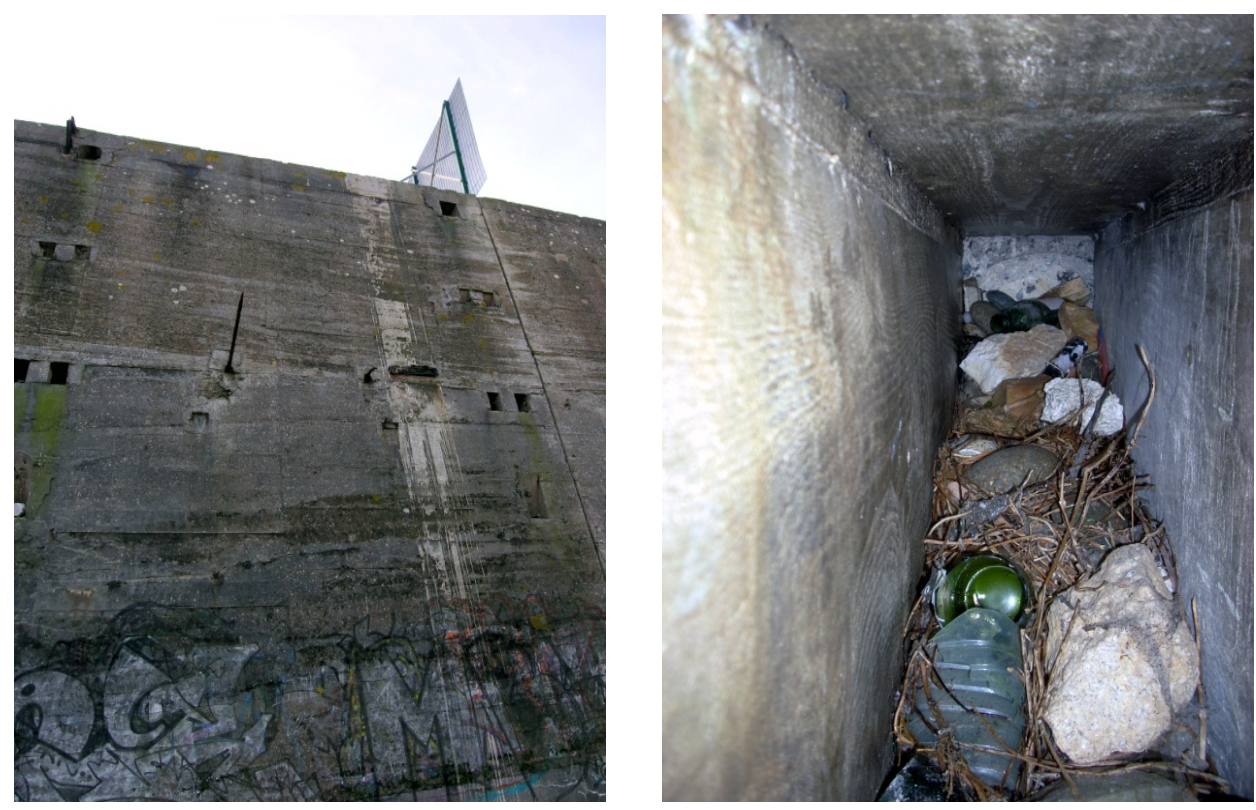

Figure 26. Camp Todt - details of the massive wall.
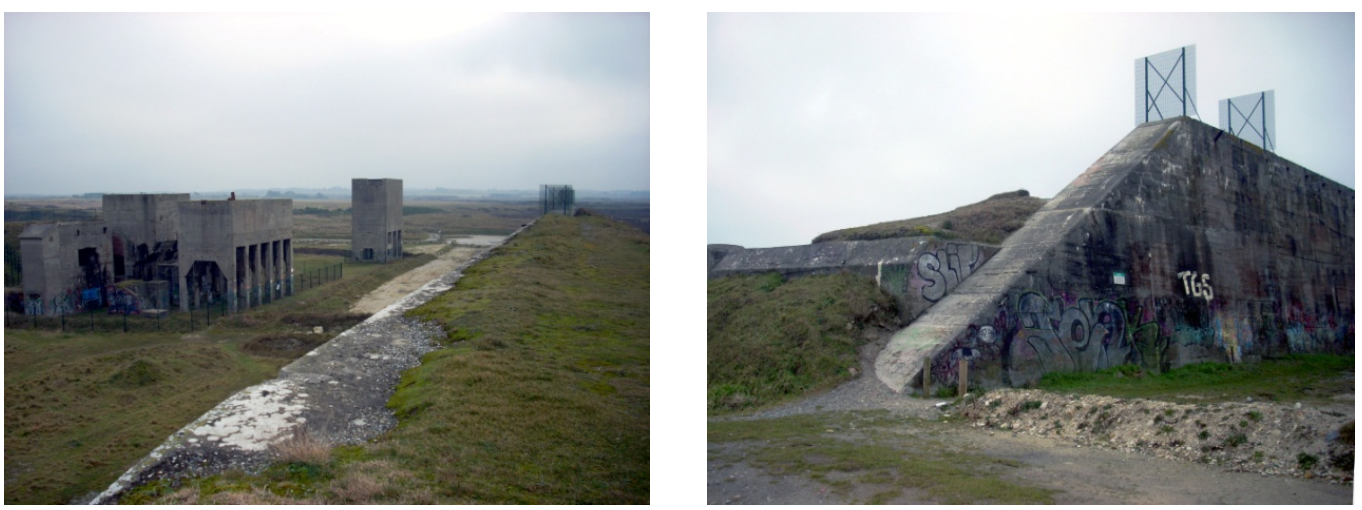

Figure 27. Camp Todt-remains of the crusher building, first and second silo, massive wall and Wn. Qu. 40 bunker H672.

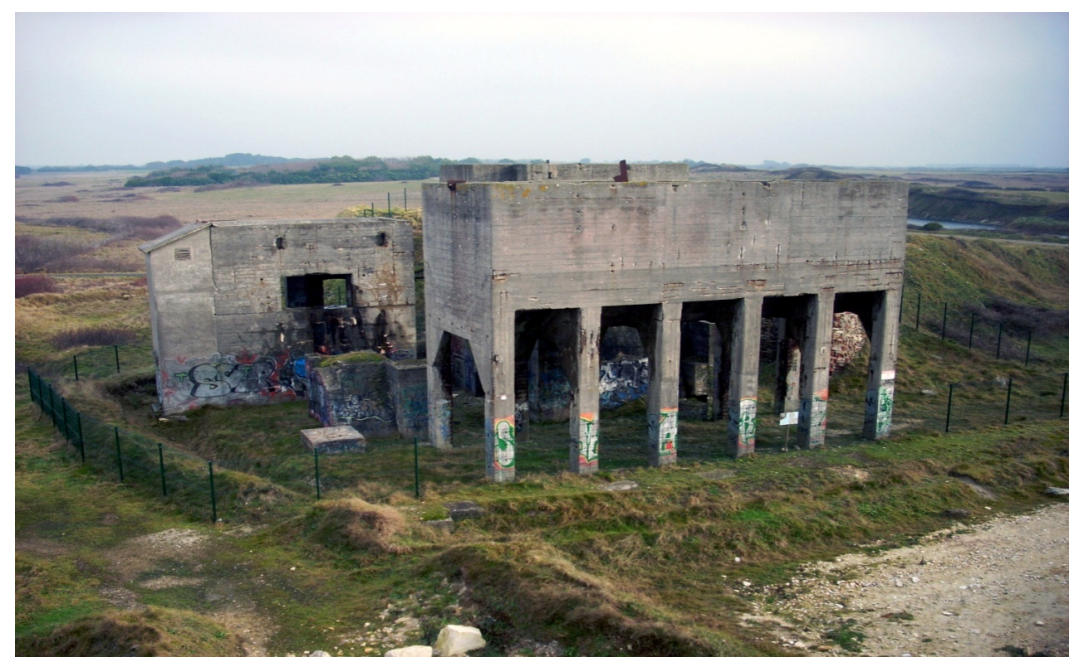

Figure 28. Camp Todt-remains of the crusher building, on the left electric distribution cabin and first crusher compartment, in the middle the first silo for crushed pebbles. 

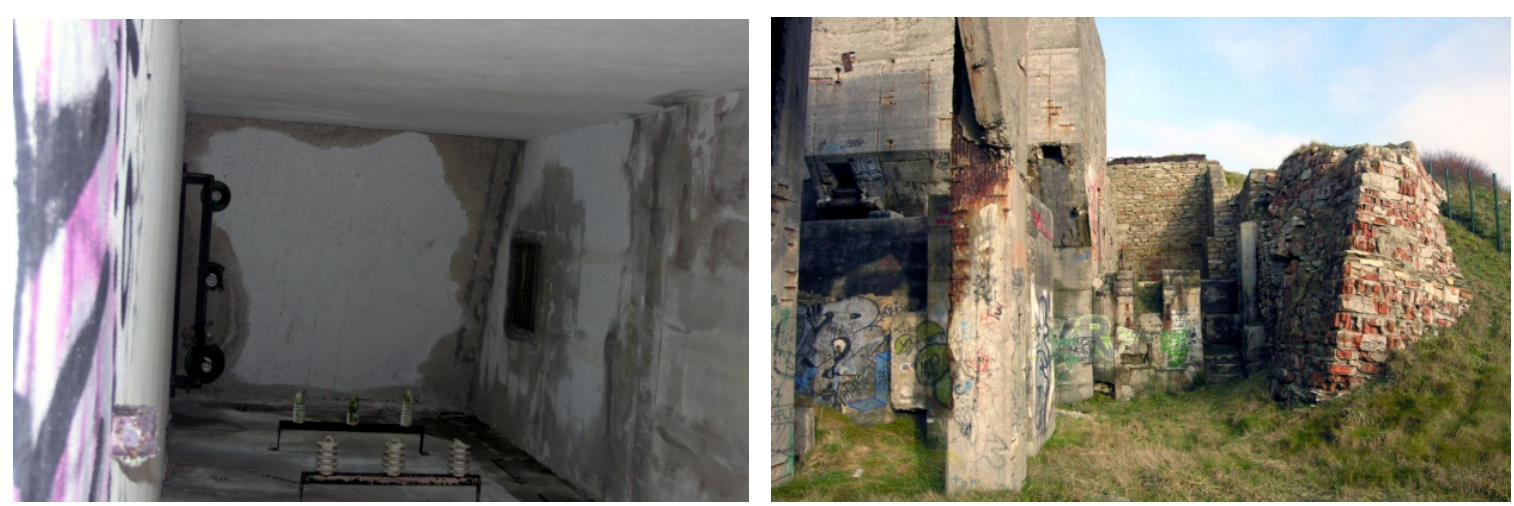

Figure 29. Camp Todt-interior of the electric distribution cabin and remains of brick walls of the crusher building.
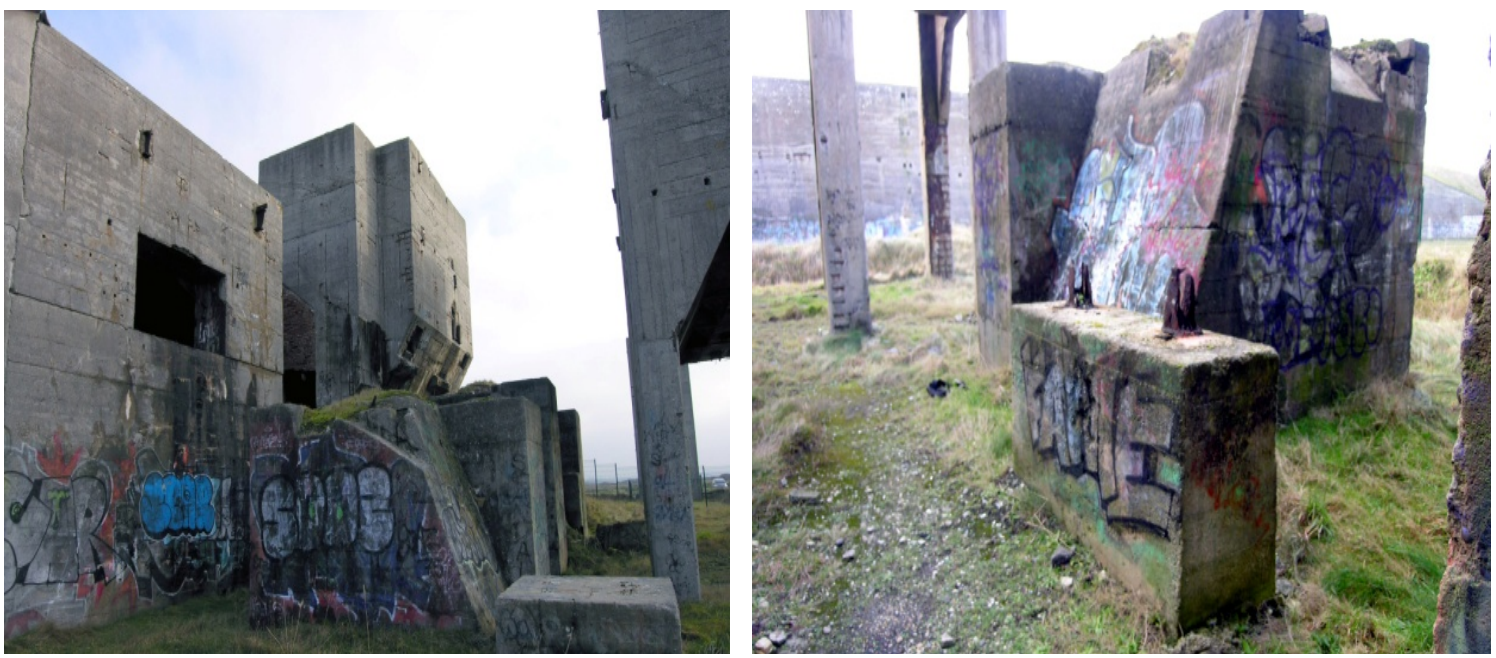

Figure 30. Camp Todt-first and second crushes compartment and concrete supports for the loading mechanism of crushed pebbles in the first concrete silo.
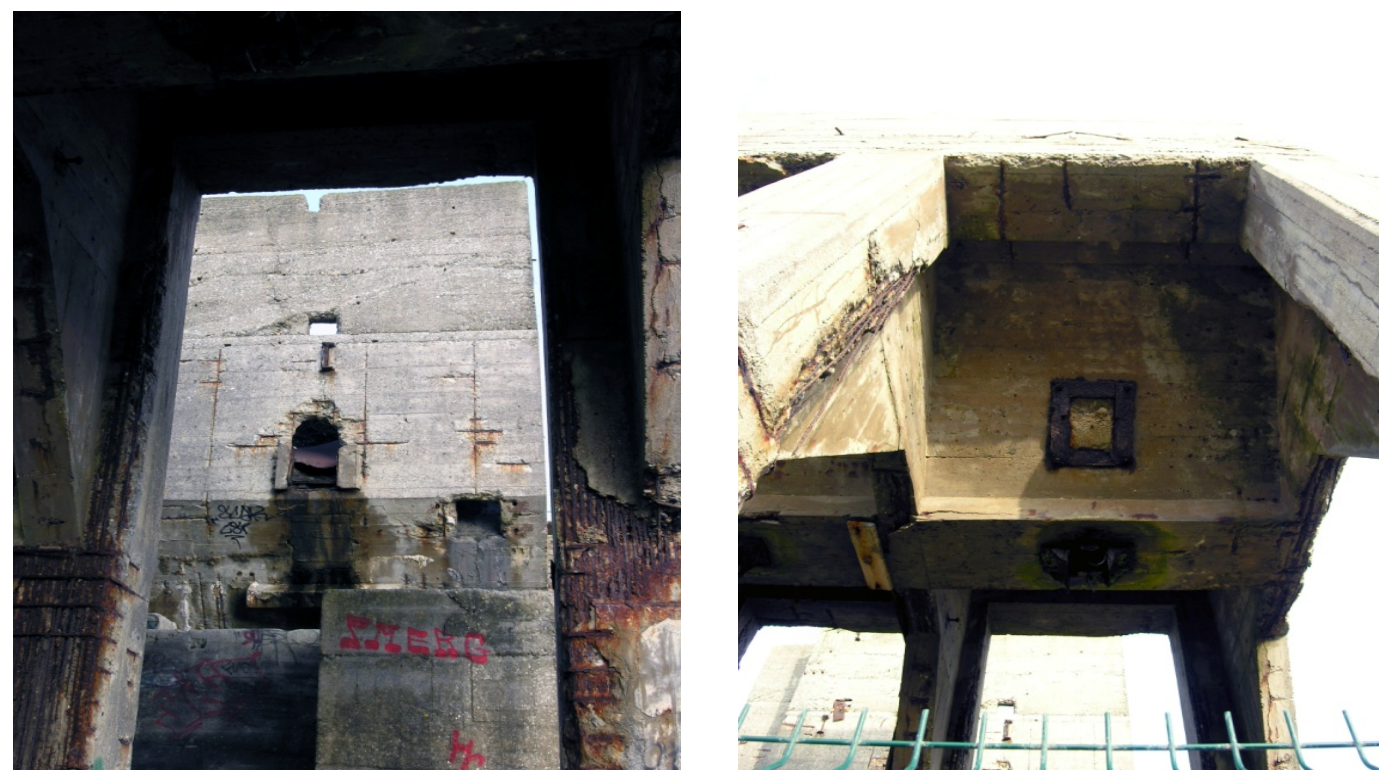

Figure 31. Todt Camp - release door for the crushed pebbles of the second crusher compartment and release doors for the crushed pebbles of the first silo for charging the crushed pebbles on wagons. 


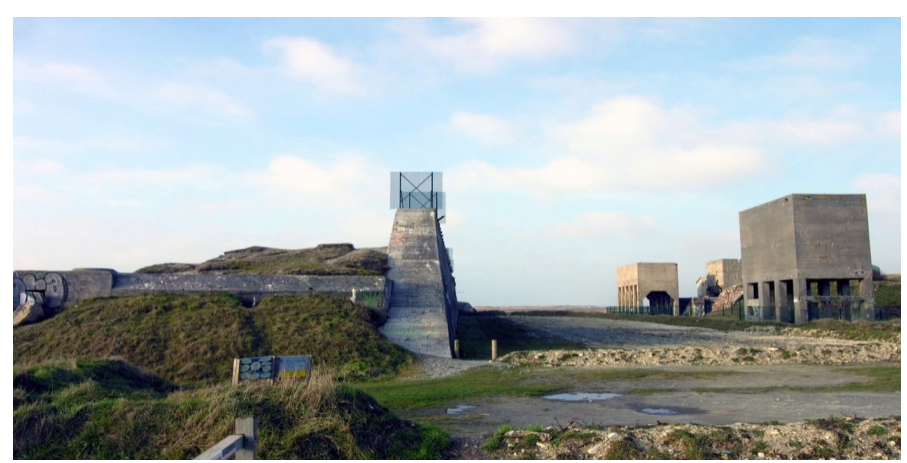

Figure 32. Wn. Qu. 40 and Camp and that Todt-from left to right, H672 with annexed tobruch, the massive wall and the remains of the Camp Todt.

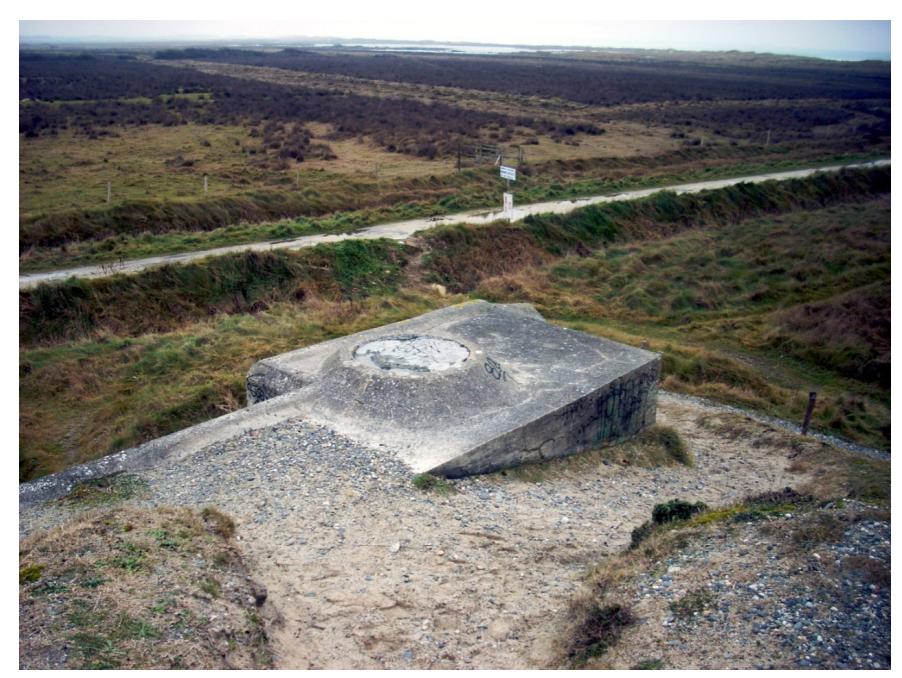

Figure 33. Wn. Qu. 40 - tobruck annexed to the bunker H672 bunker, on the topside the coast path (16).

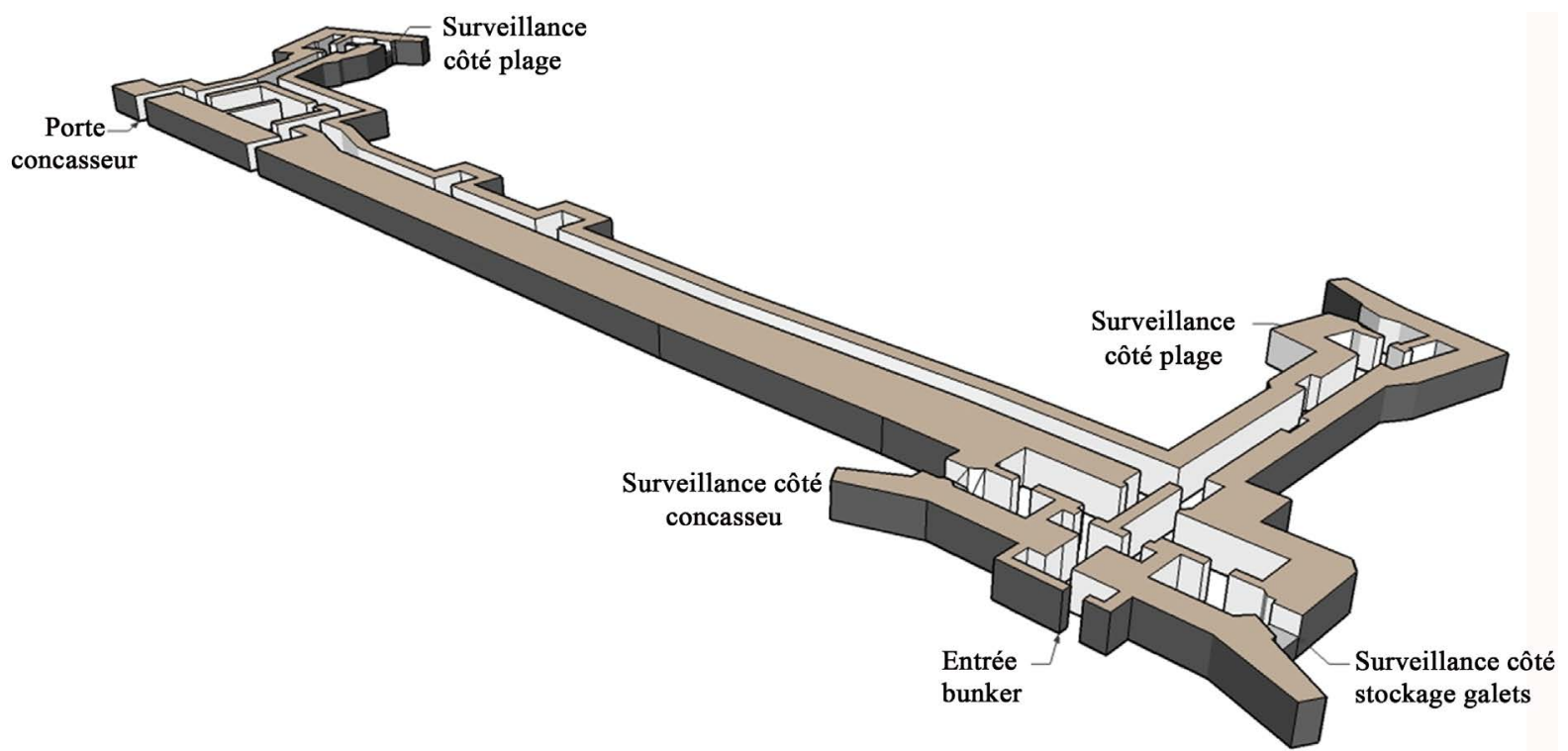

Figure 34. Wn. Qu. 40 - on the upper left: entrance bunker and first Vf beach surveillance bunker, in the middle internal connection passage between unkers, on the lower rightside second Vf beach surveillance bunker and Camp Todt Vf surveillance bunker formed by two coupled Vfs. 

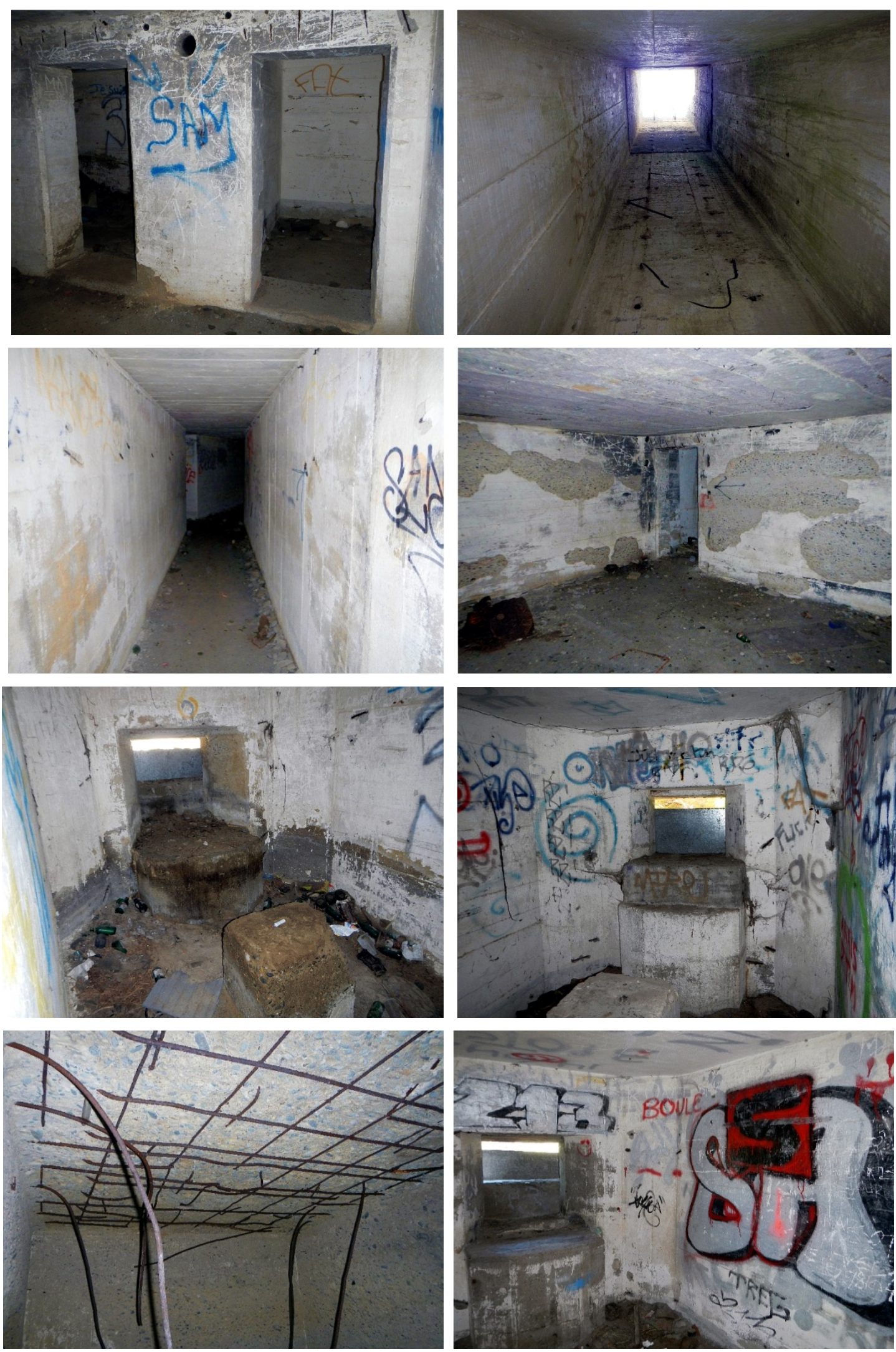

Figure 35. Wn. Qu. 40 - details of the connecting passage and the firing chamber sofa Vf bunker. 

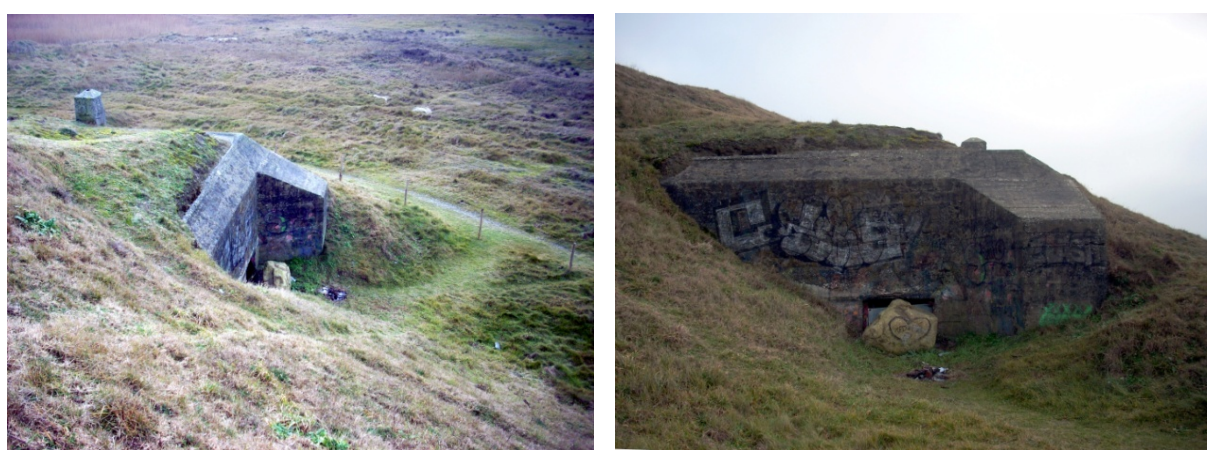

Figure 36. Wn. Qu. 40 - external details of the second Vf beach surveillance bunker.

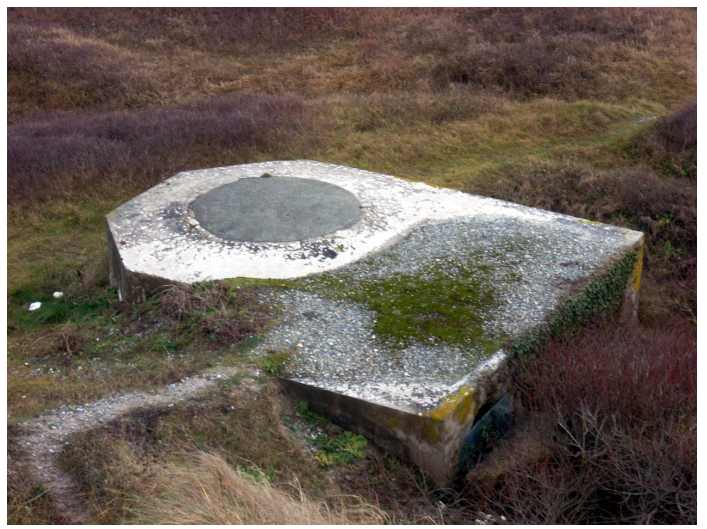

Figure 37. Wn. Qu. 40-Vf61a mortar tobruck.

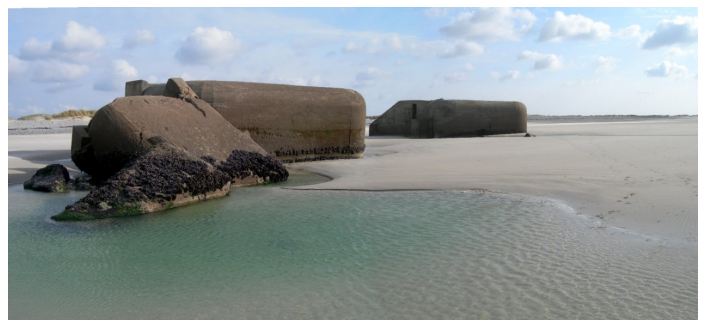

Figure 38. Wn. Qu. 32 - northern view, from left to right: H667 with protective wing partially destroyed and covered with sand, H134, H501.

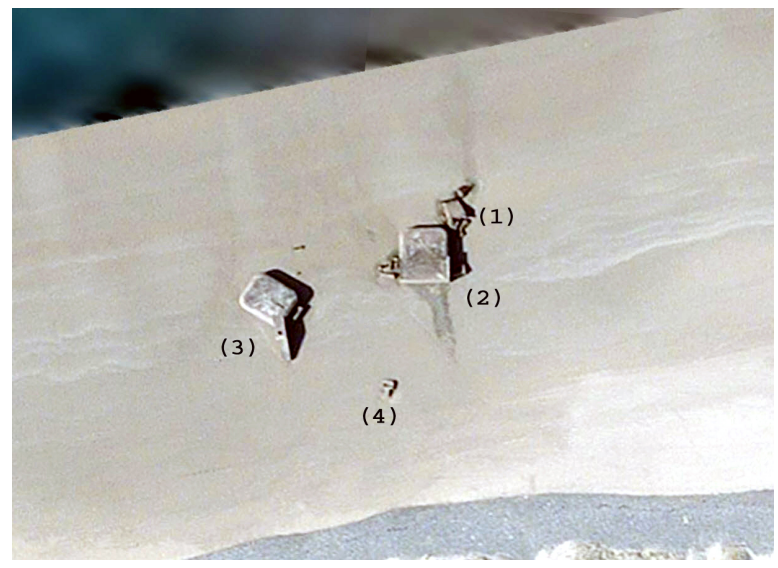

Figure 39. Wn. Qu. 32 - generalorganization: (1) H667, (2) H134, (3) H501 and (4) H58c (Flash Earth). 


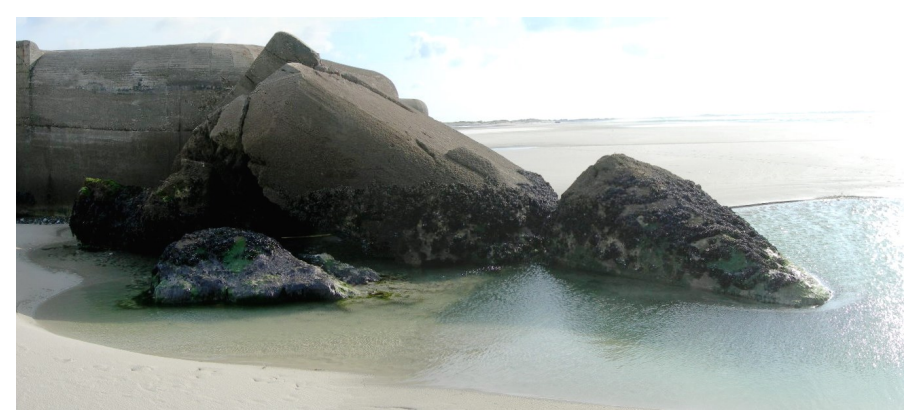

Figure 40. Wn. Qu. 32-H667 partially destroyed.

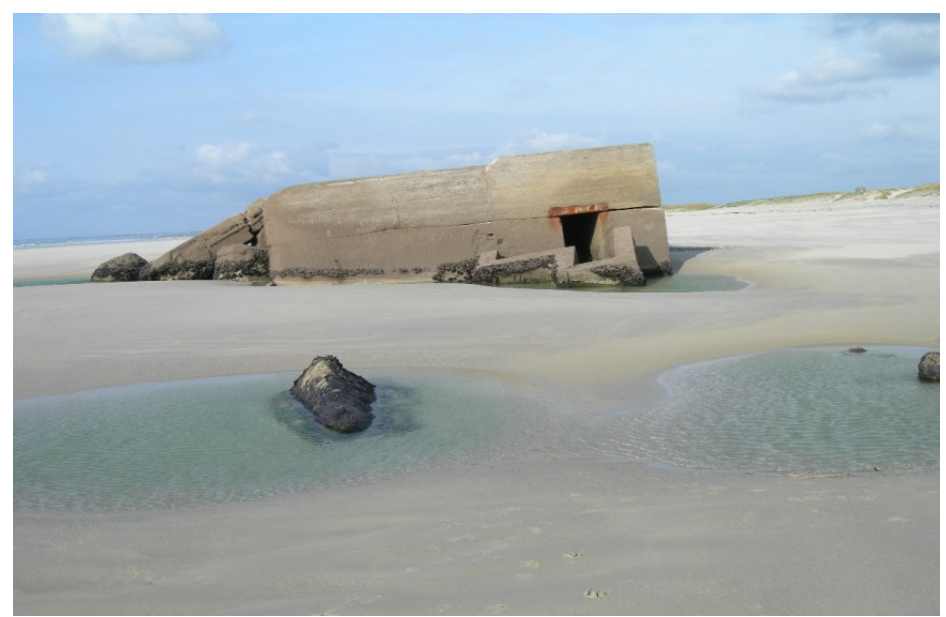

Figure 41. Wn. Qu. 32-H134 south entrance.
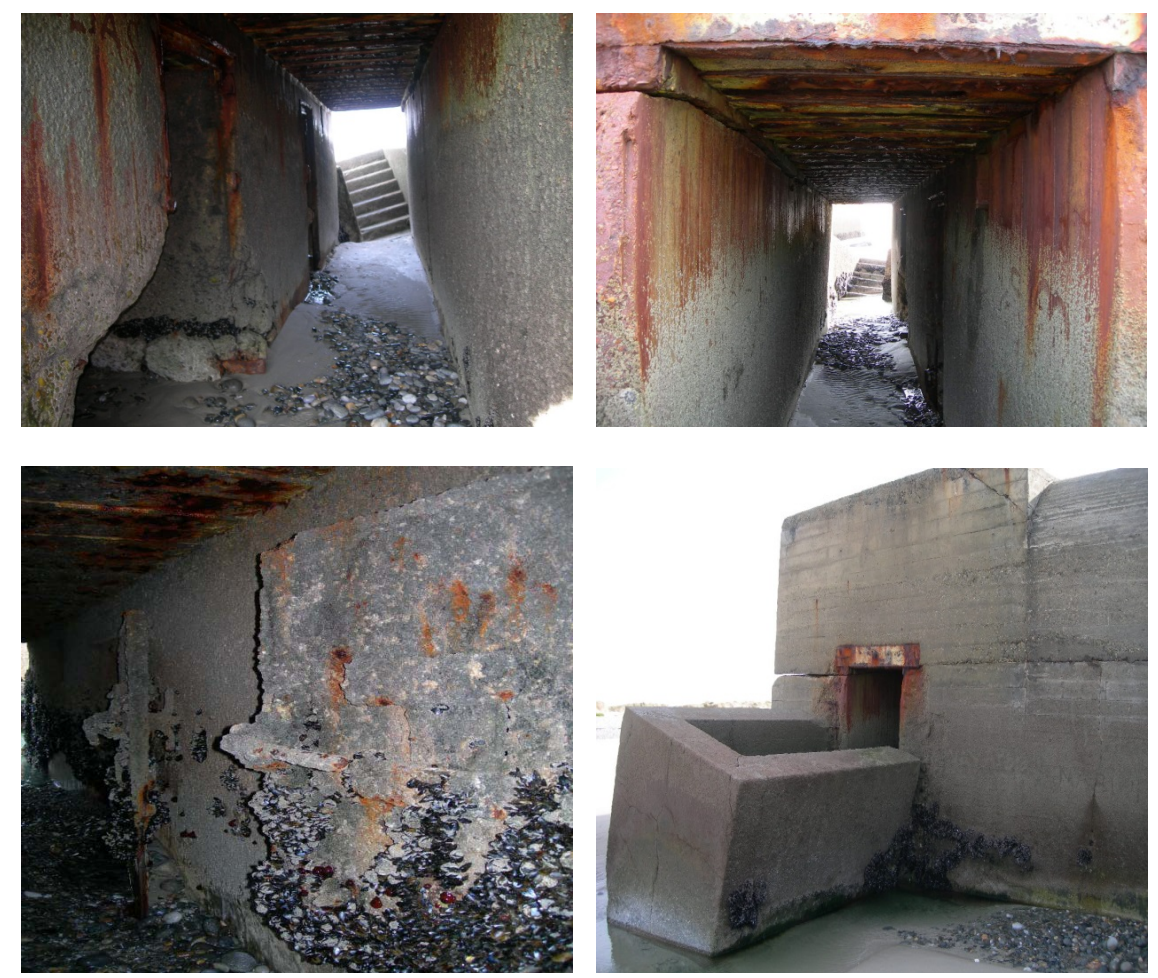

Figure 42. Wn. Qu. 40-(1) H134 details of the internal passage and the north entrance. 

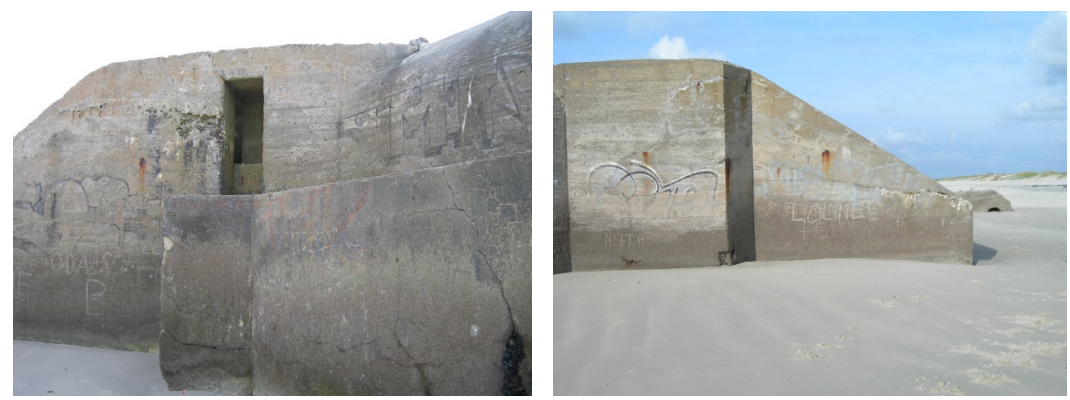

Figure 43. Wn. Qu. 40-H501 details.

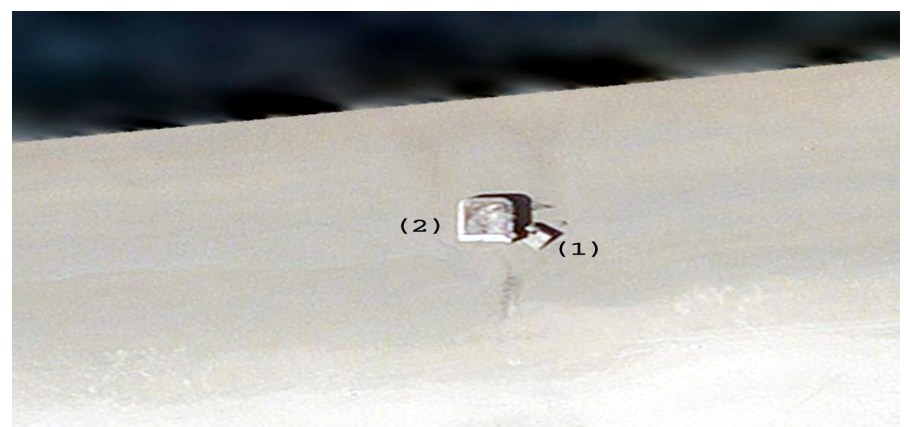

Figure 44. Wn. Qu. 41-(1) H 667 and (2) H 134 (Flash Earth).

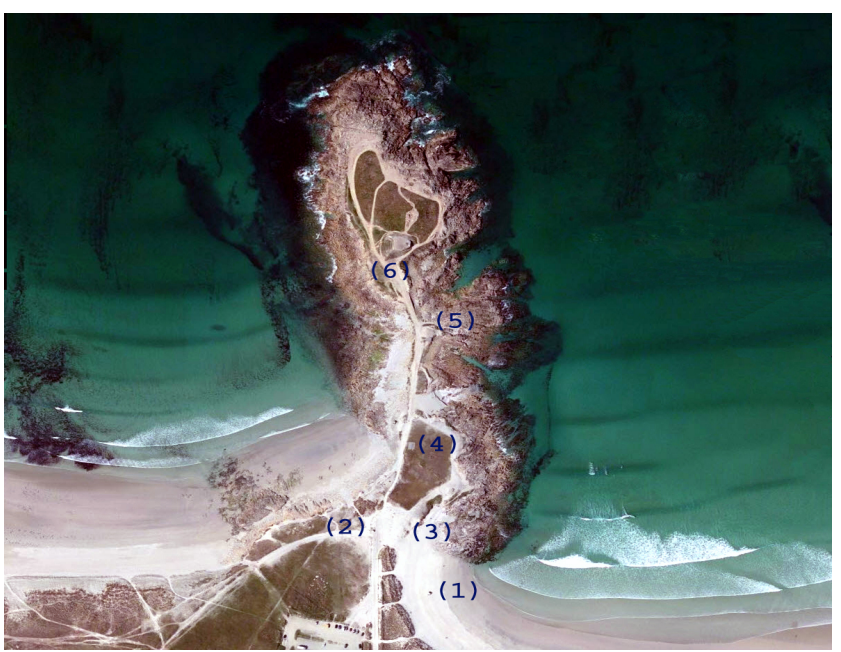

Figure 45. Wn. Qu. 42 general organization: (1) - (3) H58c, (4) H501, (5) Vk and (6) H611.
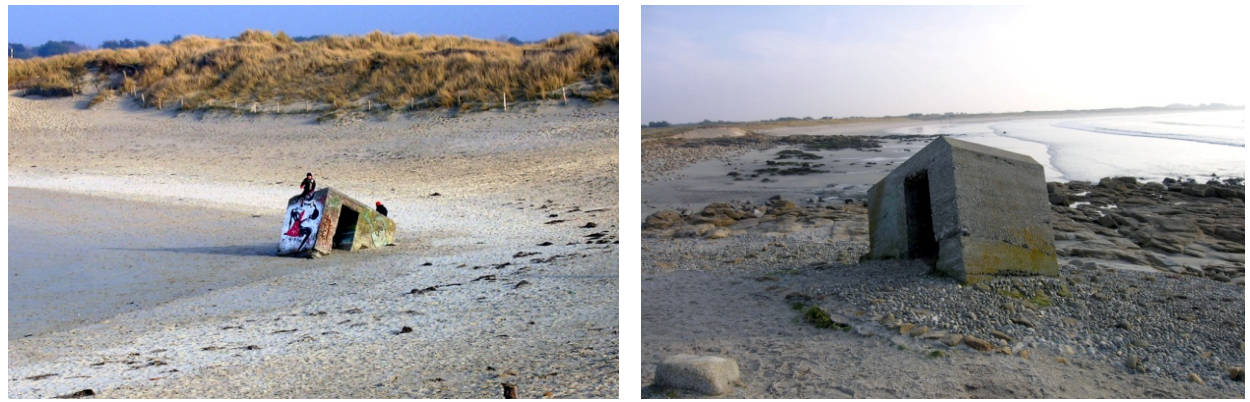

Figure 46. Wn. Qu. 42-(1) H58c and (2) H58c. 


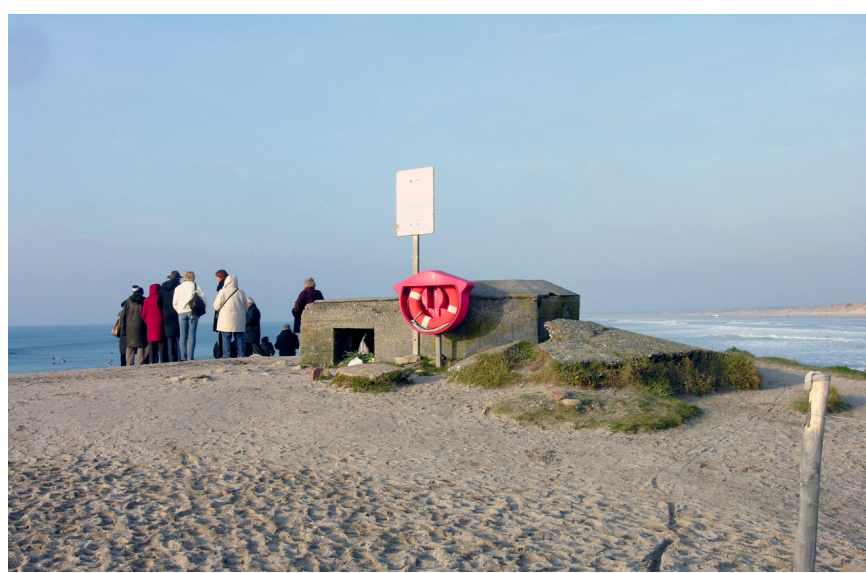

Figure 47. Wn. Qu. 42-(3) H58c.
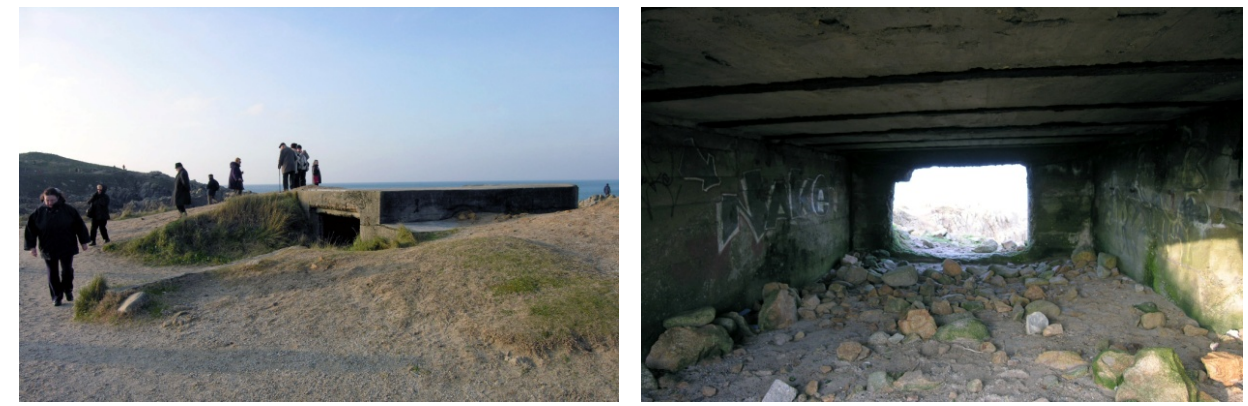

Figure 48. Wn. Qu. 42-bunker Vk, Pak details of the exterior and of the firing chamber.
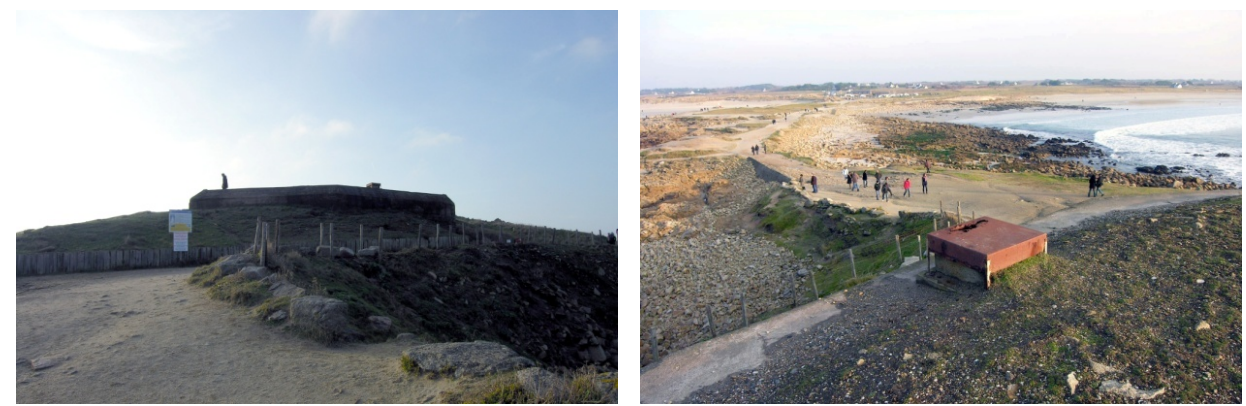

Figure 49. Wn. Qu. 42-H611 details of the exterior.

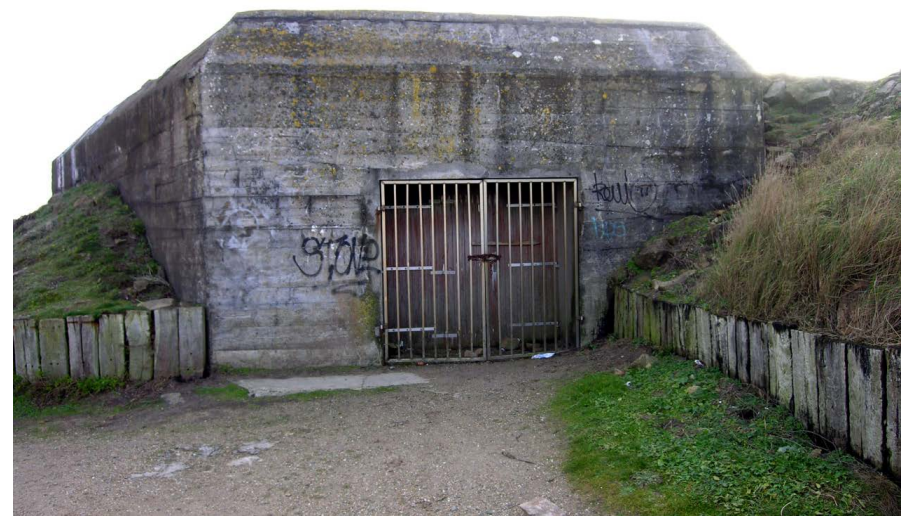

Figure 50. Wn. Qu. 42-H611 embrasure of the firing chamber. 


\section{Conclusion}

We are happy because this article has permitted us to put order in a lot of our information about the strategic role of the Tronoën beach and the Ero Vili in the $2^{\text {nd }}$ World War and to present our information to a wider public of experts and amateurs. We hope that this article will stimulate possible further studies on other events, wrongly considered as secondary in the $2^{\text {nd }}$ World War, because they influence military operations, life and fate of thousands of men.

\section{Acknowledgements}

We thank Mr. A. Le Berre for having shared us his documentation, his images and his local knowledge and for having revised this article.

\section{References}

Boderé, J.-C. (1973). Les grès coquillières d'estran du sud de la baie d'Audierne. Penn ar Bed, 9, 28-35.

Bohn, É. (2014). Tréguennec. L'usine à galets des nazis, Le Télégramme, 23 février 2014,photo d'archives Y. Marzin. http://www.letelegramme.fr/histoire/treguennec-l-usine-a-galets-des-nazis-23-02-2014-10048893.php?annonces=1

Chazette, A., Destouches, A., \& Paich, B. (1995). Album Mémorial Atlantikwall, Le Mur de L'Atlantique en France 1940-1944, ed. Heimdal, ISBN 2.84048-088-3.

Doaré, J.-J., \& Le Berre, A. (2006). Pointe de Cornuaille 1940-1944, AS3P, ISBN 2-9524073-0-4.

Dupont, A., \& Peyle, E. (1994). Le Mur de l'Atlantique sur la Côte d'Emeraude, ed. Danclau, ISBN 2-907019-20-1.

Duquesne, R. (1976). Normandie 44 Le Mur de L'Atlantique, Batteries d'Artillerie Côtière, ed. Heimdal, Bayeux.

Giot, P.-R. (1998). La dune ancienne de la baie d'Audierne. Norois, 179, 487-494. http://dx.doi.org/10.3406/noroi.1998.6889 http://www.persee.fr/web/revues/home/prescript/article/noroi 0029-182X_1998 num 179_1_6889

Le Berre, A. (2008). 39-45, N. 258, 62-72.

Lippmann, H. (1995). Bildband Heeres-Regelbauten, Sonderheft 30, Deutsches Atlantikwall Archiv, Köln, ISSN 09475575, ISBN 3-931032-30-2.

Pennmarc'h, M. (2014). N 102 .

Rolf, R. (1988). Typologie du Mur de l'Atlantique, Beetsterzwaag, ISBN 90-6476-045-3, NUGI 923.

Vergereau, P. (2014). Le Télégramme, 08 septembre 2014.

Archive A. Le Berre: Figures 6-8;

Archive Y. Marzin: Figures 2-5, 16, 19, 34-35, and 41-43;

Archive G. Tomezzoli: Figures 1, 9-15, 17-18, 20-33, 36-40, and 44-50. 